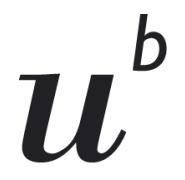

b UNIVERSITÄT

BERN

Faculty of Business, Economics and Social Sciences

Department of Economics

Monetary Policy with Reserves and CBDC:

Optimality, Equivalence, and Politics

Dirk Niepelt

20-18

November 2020 


\title{
Monetary Policy with Reserves and CBDC: Optimality, Equivalence, and Politics*
}

\author{
Dirk Niepelt ${ }^{\dagger}$
}

November 16, 2020

\begin{abstract}
We analyze policy in a two-tiered monetary system. Noncompetitive banks issue deposits while the central bank issues reserves and a retail CBDC. Monies differ with respect to operating costs and liquidity. We map the framework into a baseline business cycle model with "pseudo wedges" and derive optimal policy rules: Spreads satisfy modified Friedman rules and deposits must be taxed or subsidized. We generalize the Brunnermeier and Niepelt (2019) result on the macro irrelevance of CBDC but show that a deposit based payment system requires higher taxes. The model implies annual implicit subsidies to U.S. banks of up to 0.8 percent of GDP during the period 1999-2017.
\end{abstract}

JEL codes: E42, E43, E51, E52

Keywords: Reserves, deposits, central bank digital currency, monetary policy, Friedman rule, equivalence, Ramsey policy, bank profits, money creation

\footnotetext{
${ }^{*}$ We are grateful to David Andolfatto and Remo Taudien for valuable discussions; Luca Benati for help with the data; Pablo Kurlat for sharing his data on risk-free rates and deposit rates; as well as Lorenz Driussi, Martín Gonzalez-Eiras, and Fabienne Schneider for helpful comments.

${ }^{\dagger}$ Study Center Gerzensee; University of Bern; CEPR; CESifo. dirk.niepelt@vwi.unibe.ch, www.niepelt.ch.
} 


\section{Introduction}

Fast technological and structural change in the payment industry as well as central bank backed initiatives in countries such as Uruguay, Sweden or China have rekindled interest in fundamental questions about the monetary system 1 In modern economies this system typically exhibits two tiers: While nonfinancial institutions in the private sector use deposit liabilities of banks (and claims on deposits) as payment instruments, banks themselves pay each other with reserves that are issued by the central bank. The prospect of retail central bank digital currency (CBDC) or "Reserves for All" brings that division into question. ${ }^{2}$

Even where no CBDC has been introduced yet (that is, in most countries) the twotiered monetary system has recently undergone substantial change. In the wake of the financial crises that erupted in 2007 balance sheets of central banks have lengthened and money multipliers have collapsed, see figure 1: Reflecting quantitative easing, tightened liquidity regulation, and other factors more and more deposits and other bank liabilities that nonbanks use for payments are "backed" by claims that banks hold vis-a-vis the central bank ${ }^{3}$ Grassroots movements such as the Swiss "Vollgeld" initiative may have failed to outlaw private money creation, but the world of payments today resembles a "Vollgeld" system much more closely than fifteen years ago

In this paper, we subject the two-tiered monetary system, a purely CBDC-based monetary arrangement, as well as an integrated system with deposits, reserves, and CBDC to a positive and normative analysis. The questions we address include: What are the characteristics of optimal monetary policy in a two-tiered system? Does the introduction of CBDC alter equilibrium outcomes? If so, what monetary arrangement and money multiplier is preferable on efficiency grounds? And, which payment system imposes a higher burden on taxpayers, with possible repercussions for its political support? As a byproduct of the answers to these questions we quantify the support that banks receive from (implicit or explicit) lender of last resort guarantees by the central bank. We find that implicit subsidies in the U.S. were on the order of up to 0.8 percent of GDP in some years but negligible or even negative in others.

Our framework embeds a banking sector, deposits, reserves, and CBDC into the baseline business cycle model; it can also be viewed as an extended Sidrauski (1967) model. Households value goods, leisure, and the liquidity services provided by deposits and CBDC. Neoclassical firms produce using labor and physical capital. Banks invest in capital and reserves. Their main funding base are deposits and competition on the market for deposits is limited (Drechsler et al., 2017). The central bank issues CBDC and reserves which banks use to settle interbank payments. Managing the payment system

\footnotetext{
1 "Libra" which is backed by the Libra Association (libra.org) probably constitutes the primary example of technology driven change. For an overview of ongoing CBDC projects see for example Auer et al. (2020).

${ }^{2}$ Far into the twentieth century central banks commonly offered accounts also to nonbanks $(\overline{\mathrm{BIS}}, \overline{2018})$.

${ }^{3}$ Cash balances have also risen over the last decade. But the fall in money multipliers is predominantly a consequence of increased reserves holdings by banks.

4 "Positive Money" (positivemoney.org), the Swiss "Vollgeld" initiative (www.vollgeldinitiative.ch/english), and other grassroots movements in several countries aim to curb inside money creation. See Knight et al. (1933) and Fisher (1935) for early related proposals.
} 


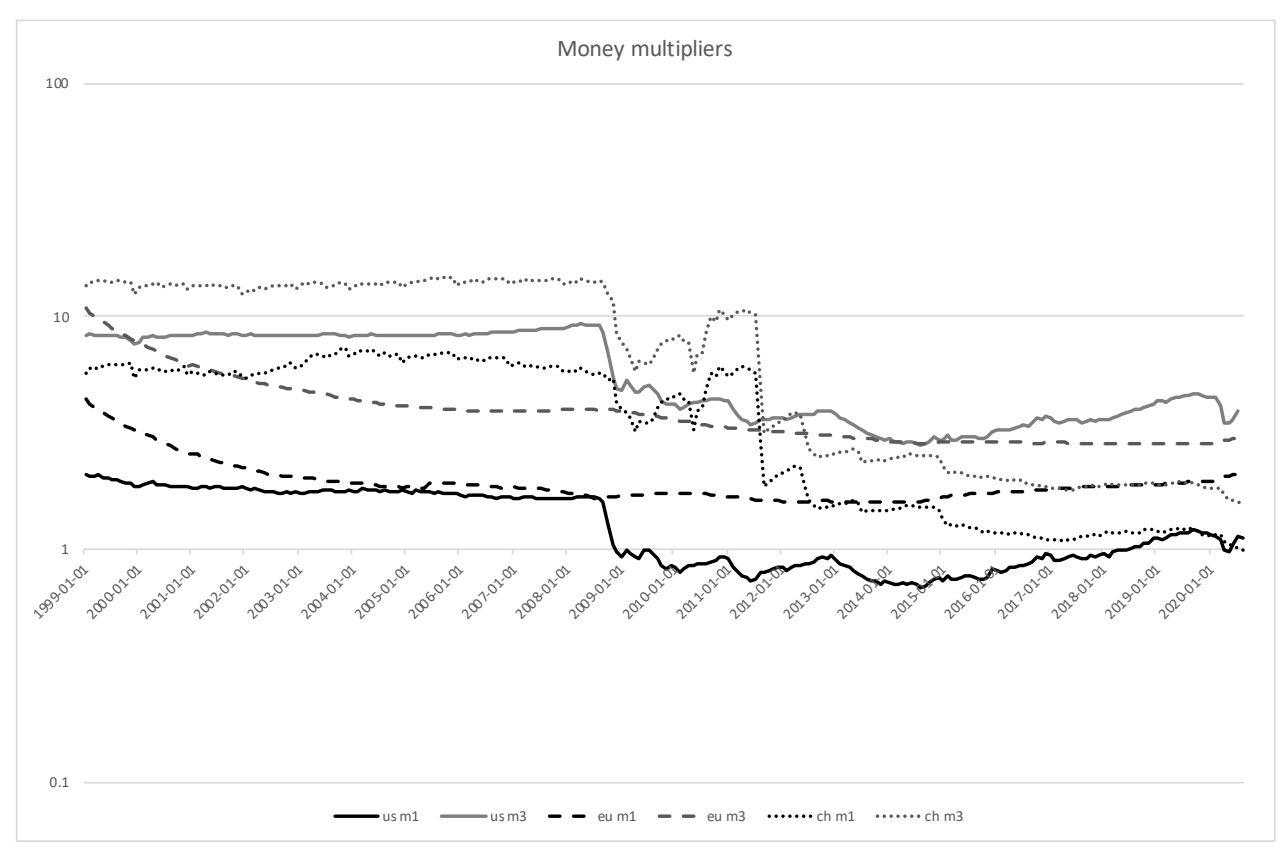

Figure 1: Money multipliers for M1 and M3 in the U.S., the Euro area, and Switzerland.

requires resources. Deposits, CBDC, and reserves may differ both with respect to their liquidity services and resource requirements for payments. As shocks affect the payment system the liquidity benefits for banks of holding reserves vary over time. The main policy instruments of the consolidated government sector include the interest rates on reserves and on CBCD as well as bank subsidies which help to address the lack of competition in the banking sector.

Our positive analysis starts with a characterization result: The equilibrium conditions in the economy with a two-tiered monetary system parallel those in the standard real business cycle model, augmented by "pseudo wedges" in the Euler equation, the laborleisure first-order condition, and the resource constraint. Under standard functional form assumptions the pseudo wedges reduce to simple summary statistics of structural shocks to the payment system as well as two policy instruments - the liquidity premium on reserves and the bank subsidy. Structural change in the payment system and policy changes therefore affect business cycle dynamics in similar ways as distorting labor-income and consumption taxes and government consumption. Along a balanced growth path there is no intertemporal pseudo wedge relative to the baseline business cycle model but there are pseudo wedges in the intratemporal first-order condition and the resource constraint.

The equilibrium liquidity premium on deposits reflects the degree of competition in the banking sector; bank subsidies; the liquidity premium on reserves; as well as the structural shocks to the payment system which affect the benefits for banks of holding reserves. We allow for two types of such benefits, internal and external. Banks internalize the former but not the latter, for example because they take into account that liquidity shortages might trigger costly asset liquidation while disregarding the fact that fire sales also affect other financial institutions. The parameter determining the internal benefits affects banks' 
operating costs both directly and indirectly, through its effect on banks' choice of reserve holdings. Accordingly, higher internal benefits of reserve holdings may raise or lower the equilibrium deposit rate. In contrast, higher external benefits unambiguously lower deposit rates.

Our positive results also let us compare the effectiveness of policy responses at a "reversal interest rate." When the equilibrium deposit rate hits a threshold level policy makers can intervene in two ways to push the rate back up above that threshold level: by raising the interest rate on reserves, or by subsidizing deposits. We find that raising the interest rate on reserves is fiscally cheaper than raising subsidies when the external component of the benefits of reserve holdings is important or the risk-free interest rate on illiquid assets small.

Next, we analyze optimality. We start by characterizing the outcome chosen by a social planner that is only constrained by production and payment technology. Not surprisingly, a modified Friedman (1969) rule emerges: Households are satiated with liquidity up to the point where liquidity benefits equal the social (resource) costs of managing liquidity. In the case of CBDC these costs are the CBDC operating costs, which are borne by the central bank. In the case of deposits they are the deposit operating costs, which are borne by commercial banks, as well as the costs for reserve operations which are borne by the central bank. The planner relies on the cost minimizing combination of deposits and CBDC, taking the liquidity benefits of deposits relative to CBDC into account.

In contrast to the social planner, the Ramsey government controls the allocation and liquidity only indirectly, by way of setting the policy instruments. We show that nevertheless, the Ramsey government can implement the social planner allocation. In a CBDC based monetary regime this is simple. The central bank simply needs to set the interest rate on $\mathrm{CBDC}$ at a level that reflects the social costs and to price banks out of the market by setting the interest rate on reserves sufficiently low.

In a two-tiered monetary system the situation is more challenging as the government needs to correct two distortions in order to align bank incentives with societal tradeoffs. The first distortion relates to lack of competition in the banking sector which reduces the quantity of deposits (and deposit interest rates) below the socially optimal level. The second distortion relates to the fact that banks do not internalize the external benefits of their reserve holdings. The public sector can simultaneously correct both distortions by employing bank deposit subsidies and setting the interest rate on reserves appropriately. Even in a two-tiered monetary system the Ramsey policy therefore implements the first best.

The optimal subsidy on bank deposits may be positive or negative, depending on the importance of external benefits of reserves holdings. Intuitively, with large external benefits the Ramsey policy subsidizes reserves by paying high interest on reserves. This distorts the incentive for banks towards seeking more deposit financing. If the distortion is sufficiently strong to outweigh the opposite distortion due to lack of competition then the optimal deposit subsidy is negative. When external benefits of reserve holdings are absent, in contrast, then the optimal interest rate on reserves reflects the social costs of reserve operations and there is no distortion that leads banks to seek excessive deposit funding. However, the distortion due to lack of competition remains present and to counter that 
latter distortion, the Ramsey government subsidizes deposits.

Under standard functional form assumptions we derive transparent optimal policy rules for the spread on reserves and bank subsidies. The interest-rate-on-reserves-spread rule that we find is strikingly simple: The spread should equal the central bank's marginal cost of operating reserves, times the share of the benefits of reserves holdings that banks internalize. Parallel to Taylor (1993)-type interest rate rules that are motivated by the goal to stabilize inflation and output gaps, the spread rule in our model signals the appropriate monetary policy stance as far as the efficient liquidity provision is concerned. The accompanying policy rule for subsidies assures that banks' optimizing choices support the optimal liquidity provision.

Our next set of results concerns equivalence. The leading question we address is whether substitution of CBDC for deposits alters the equilibrium allocation and price system. The substitution may be partial, for instance because CBDC is introduced and some households adopt it and convert their means of payment from deposits into CBDC. Or, hypothetically, it may be complete as in a "Vollgeld" regime without private money creation 5

Building on earlier equivalence results in Brunnermeier and Niepelt $(2019)$ and Niepelt (2020) we find that a substitution of CBDC for deposits does not alter the equilibrium allocation and price system as long as the relative liquidity services of deposits and CBDC coincide with the relative resource costs that the two means of payment generate at the margin. The relative liquidity services are determined by the usefulness of deposits and CBDC for transaction purposes; the relative resource costs reflect the operating costs of deposit and CBDC based payments as well as the central bank's costs of managing reserves transactions.

In the equivalent equilibrium with $\mathrm{CBDC}$ the length of the household's balance sheet does not change since the household swaps assets (deposits, CBDC, and capital). In contrast, the balance sheet of a bank shortens because the bank holds less reserves while investing the same amount as before the intervention in physical capital. The bank funding that compensates for the reduction in deposits net of reduced reserves holdings comes from the central bank: it provides a loan to the bank which in turn is financed by the net funding the central bank gains (new CBDC holdings of households net of reduced reserves holdings by banks). ${ }^{6}$

In order to assure that the noncompetitive banks go along with these equivalent balance sheet positions the central bank loan to banks must have the same effective interest rate as the deposit funding in the equilibrium without CBDC. Since the net costs of deposit funding reflect the interest rate on deposits, the interest rate on reserves, the operating costs of deposit based payments, and bank subsidies, the equivalent central bank loan interest rate depends on all these factors as well. That is, variation in spreads on deposits or reserves, structural shocks to the payment system, and policy changes all affect the equivalent central bank loan interest rate. The formula for the equivalent central

\footnotetext{
${ }^{5} \mathrm{~A}$ complete substitution is largely hypothetical because outside the model, "money" is difficult to define and its creation by banks or other actors even harder to suppress.

${ }^{6}$ If the deposits in the initial equilibrium are not collateralized then equivalence requires that the central bank loan is not collateralized either.
} 
bank loan interest rate that we derive applies independently of specific functional form assumptions, both in- and outside the model of the paper.

We use this formula to assess the funding cost reduction for banks due to their ability to issue liquid liabilities. This funding cost reduction, which according to the logic of the model can be interpreted as a subsidy to banks, is the product of two terms: The quantity of net funding that banks generate by issuing deposits, namely the deposit base net of reserve holdings; and the liquidity premium on that funding net of deposit (and reserves) operating costs. Using U.S. data for the period 1999 to 2017 we find that the funding cost reduction for U.S. banks amounted to roughly 0.4 to 0.8 percent of GDP just before and around the financial crisis. In contrast, banks did not benefit from cost reductions, or they even bore additional funding costs, once financial markets had calmed. These numbers compare with NIPA data for financial sector profits on the order of 3 percent of GDP prior to the financial crisis, negative profits during the crisis, and 2 to 3 percent after the financial crisis.

The equivalent central bank loan rate displays a downward trend, falling by roughly 3 percent over the sample period, with some fluctuations. Prior to 2009 when the reservesto-deposits ratio was very small the equivalent central bank loan rate moved roughly in parallel with the deposit interest rate. Once the reserves-to-deposits ratio increased the equivalent loan interest rate rose as long as reserves paid lower interest than deposits since one dollar of net funding required more than one dollar of deposit funding. After 2015 the deposit rate fell short of the interest rate on reserves and this contributed negatively to the equivalent loan rate.

Finally, we briefly consider political economy implications. We show that unlike a CBDC based system a two-tiered monetary system with deposits and reserves requires fiscal support by the taxpayer, even in the absence of crises, if monetary policy is conducted optimally. We argue that this could work towards strengthening the public support for the introduction of retail $\mathrm{CBDC}$ and that it might have implications for central bank independence.

Related Literature The paper relates to an old literature that discusses two-tiered monetary systems and analyzes their properties. While money-multiplier analysis dates back at least to the 1940s, Gurley and Shaw (1960) introduce the distinction between inside money issued by banks and outside money supplied by the government. Tobin 1963 ; 1969, 1985) discusses the fractional reserve banking system and proposes a precursor to CBDC. More recently, Benes and Kumhof (2012) set up a New Keynesian DSGE model and argue that banks' money creation ex nihilo destabilizes the economy. Andolfatto (2018) studies the macroeconomic consequences of banks' money creation in an OLG framework. Faure and Gersbach (2018) contrast the welfare under a fractional reserve banking architecture and an architecture with 100\% reserve banking. In Taudien (2020) inside money issued by competitive banks reduces the financing costs of producers. $7^{7}$

Following literatures in macroeconomics and banking we assume that reserves affect

\footnotetext{
${ }^{7}$ For an analysis of complementarities between different elements in contemporary monetary systems (bank lending, insured deposits, lender of last resort, prudential supervision) see Farhi and Tirole (2020).
} 
the operating costs of banks in a deposit based payment system, without modeling the market micro structure (e.g., Bolton et al., 2020). In Kiyotaki and Moore (2019) a liquid security, like reserves, relaxes resalability constraints and increases productivity (reduces costs). Bianchi and Bigio (2020) analyze the portfolio choice of banks and monetary policy transmission in a frictional interbank market with bargaining; the shocks in their framework, which are related to matching frictions and the volatility of deposit withdrawals, can be mapped into the structural shocks we posit in the model. Parlour et al. (2020) analyze the "liquidity externality" that arises because banks need to hold reserves against claims issued by their competitors. In our model reserve holdings exert a positive externality on competitors, in addition to lowering a bank's expected operating costs.

A recent literature analyzes potential implications of the introduction of a retail CBDC 8 Barrdear and Kumhof (2016) simulate a rich DSGE model under the assumption that the introduction of CBDC lowers real interest rates and transaction costs, with macroeconomic consequences. In Keister and Sanches (2020) CBDC issuance helps to promote exchange but it may also crowd out deposits which are crucial for investment when the central bank cannot refinance banks. Keister and Sanches (2020) study the resulting tradeoff under different assumptions about the substitutability of cash, deposits, and CBDC. Böser and Gersbach (2020) argue that the introduction of CBDC in conjunction with tight central bank collateral requirements and account switching costs could render commercial bank lending nonviable. In Piazzesi and Schneider (2020) asset holdings on the balance sheet of financial institutions generate social costs and credit lines by commercial banks provide liquidity without requiring such asset holdings; this gives rise to real effects when households hold CBDC for precautionary reasons.

In Andolfatto (2019) banks have access to central bank facilities. The introduction of CBDC leads banks to adjust their pricing; it does not undermine bank lending but reduces bank rents and improves financial inclusion. Chiu et al. (2019) contains a quantitative analysis that combines elements of Keister and Sanches (2020) and Andolfatto (2019). Keister and Monnet (2020) analyze how the introduction of CBDC could shape information asymmetries between banks and the central bank and by implication, financial stability. In Williamson (2019) CBDC is a more efficient means of payment than cash but CBDC issuance forces the central bank to hold more assets and to compete with commercial banks which require assets as collateral. Our framework connects more closely to the baseline macroeconomic workhorse model and it analyzes policy in a two-tiered system in addition to studying equivalence; we abstract from cash but this is without loss of generality. ${ }^{9}$

Our equivalence result generalizes findings in Brunnermeier and Niepelt (2019). Relative to that work we introduce resource costs of operating a payment system as well as a reserves layer; we derive the equivalent central bank loan interest rate; and we use the

\footnotetext{
${ }^{8}$ See Niepelt (2018) for a review of early contributions to this literature.

${ }^{9}$ See also Niepelt (2020) and Fernández-Villaverde et al. (2020). Kahn et al. (2018), Kumhof and Noone (2018), Bindseil (2020), and Auer and Böhme (2020), among others, discuss design options for retail CBDCs. Cash could affect the bargaining power of market participants, as in Lagos and Zhang $(2020)$. While this would alter the exact equilibrium conditions it would not change the basic conclusions as far as deposits versus CBDC are concerned.
} 
latter to assess implicit bank subsidies in the U.S. Moreover, we study optimal policy when equivalence does not hold. Wallace (1981) derives an equivalence result in an OLG economy; he shows that it is irrelevant whether households hold physical capital directly or indirectly, via their money holdings at a central bank invested in capital. Bryant (1983) summarizes equivalence results. Chamley and Polemarchakis (1984) establish that open-market operations are neutral when money does not serve as a medium of exchange. Sargent (1987, 5.4) presents results on equivalent fiscal-monetary policies in the opposite case.

Our analysis of optimal monetary policy complements large literatures building on the "New Keynesian" and "New Monetarist" frameworks; for overviews, see for example Woodford (2003), Galí (2015), and Rocheteau and Nosal (2017). Unlike the "New Keynesian" framework the present paper emphasizes the role of money as a means of payment and store of value rather than unit of account; it abstracts from nominal rigidities. Unlike the "New Monetarist" framework but in line with a large literature following Sidrauski (1967) (e.g., Di Tella, 2020) the paper emphasizes connections with the baseline business cycle models used for policy analysis, rather than the market micro structure underlying the supply and demand for liquidity. Relative to typical contributions in either the "New Keynesian" or "New Monetarist" literature we analyze the role of a two-tiered monetary system, equivalence relations, implicit bank subsidies, and the consequences of introducing CBDC.

Structure of the Paper The remainder of the paper is structured as follows. Section2 lays out the monetary economy and section 3 characterizes general equilibrium. In section 4 we analyze the social planner outcome and the Ramsey policy. Section 5 assesses the equivalence of monetary arrangements with deposits and reserves versus CBDC, and we quantify the implicit bank subsidies in a deposit based monetary system. Section 6 briefly considers political economy aspects and section 7 concludes.

\section{A Monetary Economy}

We consider an infinite horizon production economy with a continuum of mass one of homogeneous infinitely-lived households. The households own a succession of two-periodlived, monopsonistic banks and of one-period-lived, competitive firms. Monetary and fiscal policy is determined by a consolidated government/central bank.

The model extends the framework in Sidrauski (1967) threefold. First, it features two means of payment at the retail level, issued by banks and the central bank respectively; one can think of the two as deposits on the one hand and central bank digital currency (CBDC) or "reserves for all" on the other. Second, it allows for resource costs of circulating these means of payment and running the payment system. Finally, the model features a reserve layer: In addition to possibly serving as a payment provider for households (by issuing CBDC) the central bank settles payments between banks; the means of payment for such settlements is another central bank liability - reserves. This setting conforms to the typical arrangement in modern economies where the settlement of customer transactions 
between banks occurs through a central-bank-run payment system.

\subsection{Households}

The representative household takes prices, returns, profits, and taxes as given and solves

$$
\begin{array}{ll} 
& \max _{\left\{c_{t}, x_{t}, k_{t+1}, m_{t+1}, n_{t+1}\right\}_{t \geq 0}} \sum_{t=0}^{\infty} \beta^{t} \mathbb{E}_{0}\left[u\left(c_{t}, z_{t+1}, x_{t}\right)\right] \\
\text { s.t. } & k_{t+1}+m_{t+1}+n_{t+1}=k_{t} R_{t}^{k}+m_{t} R_{t}^{m}+n_{t} R_{t}^{n}+w_{t}\left(1-x_{t}\right)+\pi_{t}-c_{t}-\tau_{t}, \\
& k_{t+1}, m_{t+1}, n_{t+1} \geq 0 .
\end{array}
$$

Here, $c_{t}$ and $x_{t}$ denote household consumption of the good and leisure at date $t$, respectively, and $z_{t+1}$ denotes "effective real balances" carried from $t$ into $t+1$. Effective real balances are a weighted sum of (real) base money held by nonbanks, $m_{t+1}$, and bank deposits, $n_{t+1}$,

$$
z_{t+1} \equiv \lambda_{t} m_{t+1}+n_{t+1}
$$

We typically refer to $m_{t+1}$ as "money" (CBDC) and to $n_{t+1}$ as "deposits." The parameter $\lambda_{t}>0$ indexes the liquidity benefits of money relative to those of deposits. While we assume that the parameter is exogenous many of our results do not require that assumption: Even if $\lambda_{t}$ were endogenous, for instance as a function of $m_{t+1}$ and $n_{t+1}$, many key results and their intuitions would go through (at least locally) but the representation of the results would be less transparent. Also, we abstract from cash and conjecture that this simplification is not important either 10

The felicity function $u$ is increasing, strictly concave, and satisfies Inada conditions; the discount factor $\beta$ is positive and strictly smaller than unity. As is well known, this "money in the utility function" specification can represent several monetary frictions, including a "shopping time" friction which renders real balances helpful to economize on time spent shopping consumption goods 11 All key results of the paper are robust to changes in the assumptions that give rise to a demand for liquidity. What matters is not why households demand liquidity services, but only that they do so.

Equation (1) represents the household's budget constraint. It states that the household invests in capital, $k_{t+1}$, as well as real balances. The household finances these investments as well as consumption outlays and taxes, $\tau_{t}$, out of wage income, which equals the product of the wage, $w_{t}$, and labor supply, $1-x_{t}$; distributed profits, $\pi_{t}$; and the gross return on its portfolio. The latter consists of the returns on capital, $k_{t} R_{t}^{k}$, money, $m_{t} R_{t}^{m}$, and deposits, $n_{t} R_{t}^{n}$. The gross rates of return on money and deposits, $R_{t}^{m}$ and $R_{t}^{n}$ respectively, reflect both nominal interest rates and inflation; the decomposition between the two components is irrelevant for now.

\footnotetext{
${ }^{10}$ Our key results concern the societal tradeoffs between deposits and money. We conjecture that these tradeoffs would not fundamentally be altered in the presence of cash.

${ }^{11}$ See Saving (1971), McCallum and Goodfriend (1987), Feenstra (1986), and Croushore (1993). We do not aim to provide micro-foundations for the retail demand for means of payment but to model the composition of monetary balances given such demand, whatever its sources are.
} 
For simplicity, we do not index variables and parameters by history. Variables $c_{t}, x_{t}$, $k_{t+1}, m_{t+1}, n_{t+1}, z_{t+1}, R_{t}^{k}, R_{t+1}^{m}, R_{t+1}^{n}, w_{t}, \pi_{t}, \tau_{t}$ and parameter $\lambda_{t}$ are measurable with respect to information available at date $t$. That is, real interest rates on deposits and money are risk-free (inflation risk is negligible) while the rate of return on capital may be risky.

In equilibrium capital holdings and real balances are strictly positive. The household's optimality conditions are given by the following Euler equations for $k_{t+1}, m_{t+1}, n_{t+1}$, and $x_{t}$ :

$$
\begin{aligned}
& u_{c}\left(c_{t}, z_{t+1}, x_{t}\right)=\beta \mathbb{E}_{t}\left[R_{t+1}^{k} u_{c}\left(c_{t+1}, z_{t+2}, x_{t+1}\right)\right], \\
& u_{c}\left(c_{t}, z_{t+1}, x_{t}\right) \geq \beta R_{t+1}^{m} \mathbb{E}_{t}\left[u_{c}\left(c_{t+1}, z_{t+2}, x_{t+1}\right)\right]+\lambda_{t} u_{z}\left(c_{t}, z_{t+1}, x_{t}\right), \quad m_{t+1} \geq 0, \\
& u_{c}\left(c_{t}, z_{t+1}, x_{t}\right) \geq \beta R_{t+1}^{n} \mathbb{E}_{t}\left[u_{c}\left(c_{t+1}, z_{t+2}, x_{t+1}\right)\right]+u_{z}\left(c_{t}, z_{t+1}, x_{t}\right), \quad n_{t+1} \geq 0, \\
& u_{x}\left(c_{t}, z_{t+1}, x_{t}\right)=u_{c}\left(c_{t}, z_{t+1}, x_{t}\right) w_{t} .
\end{aligned}
$$

The weak inequalities in the Euler equation for $m_{t+1}$ or $n_{t+1}$, respectively, hold with equality if $m_{t+1}$ or $n_{t+1}$ is strictly positive. To express the latter two Euler equations more compactly let $\lambda_{t}^{m} \equiv \lambda_{t}, \lambda_{t}^{n} \equiv 1$, and define the risk-free interest rate, $R_{t+1}^{f}$, as

$$
R_{t+1}^{f} \equiv 1 / \mathbb{E}_{t}\left[\operatorname{sdf}_{t+1}\right]
$$

where $\operatorname{sdf}_{t+1} \equiv \beta u_{c}\left(c_{t+1}, z_{t+2}\right) / u_{c}\left(c_{t}, z_{t+1}\right)$ denotes the stochastic discount factor. When the household holds payment instruments of type $i \in\{m, n\}$ then the associated firstorder condition reads

$$
\lambda_{t}^{i} u_{z}\left(c_{t}, z_{t+1}, x_{t}\right)=u_{c}\left(c_{t}, z_{t+1}, x_{t}\right)\left(1-\frac{R_{t+1}^{i}}{R_{t+1}^{f}}\right) .
$$

When the household holds both payment instruments then, additionally,

$$
R_{t+1}^{f}-R_{t+1}^{m}=\lambda_{t}\left(R_{t+1}^{f}-R_{t+1}^{n}\right) .
$$

According to equation (4) payment instrument $i$ enjoys a liquidity premium when $\lambda_{t}^{i} u_{z}\left(c_{t}, z_{t+1}, x_{t}\right)>$ 0 . We denote this liquidity premium on payment instrument $i$ by

$$
\chi_{t+1}^{i} \equiv 1-\frac{R_{t+1}^{i}}{R_{t+1}^{f}} .
$$

Equivalently, $-\chi_{t+1}^{i}$ equals the spread on payment instrument $i$ compared with a risk-free bond which does not provide liquidity services.

When the household holds both payment instruments then, according to equation (5), the liquidity premium on money exceeds (falls short of) the liquidity premium on deposits if money is more (less) liquid than deposits $\left(\lambda_{t}>(<) 1\right)$. 


\subsection{Banks}

A bank at date $t$ issues deposits, borrows from the central bank, $l_{t+1}$, and collects government subsidies on deposits at rate $\theta_{t}$; it invests in capital and reserves, $r_{t+1} \sqrt{12}$ The bank takes the rates of return on capital and reserves, the stochastic discount factor, and the subsidy rate as given. In contrast, it chooses the quantity of deposits and central bank loans subject to the funding supply schedules of households and the central bank. Specifically, the bank acts as a monopsonist on the market for deposits.

To introduce a role for reserves we assume that larger reserves holdings relative to deposits lower the operating costs in the retail payment system, $\nu_{t}$. (We do not need to stipulate a minimum reserves requirement.) One narrative that can motivate this assumption envisions a banking sector that is segmented by region, with one monopsonistic bank in each region 13 The banks settle payments among each other (on behalf of their clients) by transferring reserves. If a bank lacks reserves to cover net payments to other financial institutions then it needs to transfer ownership of capital but this generates resource costs related to, e.g., fire sales, deadweight losses, or legal charges. As a consequence, the resource costs of running the payment system are decreasing in $r_{t+1}$ and increasing in $n_{t+1}{ }^{14}$

We also allow $\nu_{t}$ to vary with the stock of reserves and deposits of other banks. This allows us to capture positive externalities of reserves holdings. They are present, for example, when fire sales by one bank increase the costs of other institutions that lack (reserves) liquidity. Formally, letting $\zeta_{t+1} \equiv r_{t+1} / n_{t+1}$ denote the reserves-to-deposits ratio of a bank and $\bar{\zeta}_{t+1} \equiv \bar{r}_{t+1} / \bar{n}_{t+1}$ the aggregate reserves-to-deposits ratio, we make the following assumptions about operating costs: When a bank has no deposits then its operating costs equals zero; $n_{t+1}=0 \Rightarrow n_{t+1} \nu_{t}=0$. When all other institutions have no deposits $\left(\bar{n}_{t+1}=0\right)$ then the bank's operating costs per unit of own deposits are large but bounded, ruling out asymmetric equilibria with $\bar{n}_{t+1}=0$ but $n_{t+1}>0$. And in all other cases $\left(n_{t+1}>0\right.$ and $\left.\bar{n}_{t+1}>0\right) \nu_{t}$ is given by the function $\nu_{t}\left(\zeta_{t+1}, \bar{\zeta}_{t+1}\right)$, which is strictly decreasing in both arguments, strictly convex, and satisfies $\nu_{12, t}=0$ or $\nu_{11, t} \geq \nu_{22, t}$, as well as $\lim _{\zeta_{t+1} \downarrow 0} \nu_{1, t}=\infty \sqrt{15}$ These assumptions imply that in equilibrium, $\zeta_{t+1}=\bar{\zeta}_{t+1}$ and reserves are strictly positive if and only if deposits are strictly positive.

\footnotetext{
${ }^{12}$ Rather than directly investing in physical capital the bank might invest in securities (e.g., loans to companies or investment vehicles) which eventually fund physical capital accumulation. Without loss of generality we abstract from bank equity. Bank equity would finance additional capital investments by banks and it would be held by households who in turn would invest less in physical capital.

${ }^{13}$ Alternatively, we could assume that the banking sector is monopolistically (monopsonistically) competitive and effective real balances are a composite of deposit holdings at different banks. The optimality conditions of a bank in Cournot equilibrium closely parallel the conditions of a monopsony bank derived below (see, e.g., Freixas and Rochet, 2008).

${ }^{14}$ See the discussion in the literature review on models of the demand for reserves and interbank payments.

${ }^{15}$ We denote the partial derivatives of $\nu_{t}$ with respect to its first and second argument, respectively, by $\nu_{1, t}$ and $\nu_{2, t}$ and we use similar notation for higher order derivatives.
} 
The program of a bank at date $t$ reads ${ }^{16}$

$$
\begin{aligned}
\max _{n_{t+1}, l_{t+1}, r_{t+1}} & \pi_{1, t}^{b}+\mathbb{E}_{t}\left[\operatorname{sdf}_{t+1} \pi_{2, t+1}^{b}\right] \\
\text { s.t. } & \pi_{1, t}^{b}=-n_{t+1}\left(\nu_{t}\left(\zeta_{t+1}, \bar{\zeta}_{t+1}\right)-\theta_{t}\right), \\
& \pi_{2, t+1}^{b}=\left(n_{t+1}+l_{t+1}-r_{t+1}\right) R_{t+1}^{k}+r_{t+1} R_{t+1}^{r}-n_{t+1} R_{t+1}^{n}-l_{t+1} R_{t+1}^{l}, \\
& R_{t+1}^{n}, R_{t+1}^{l} \text { perceived endogenous, } \\
& n_{t+1}, l_{t+1} \geq 0
\end{aligned}
$$

where $\pi_{1, t}^{b}$ and $\pi_{2, t+1}^{b}$ denote the cash flows generated in the first and second period of the bank's operations, respectively. The first constraint relates the cash flow in the first period of operation to the operating costs net of subsidies. The second constraint relates the cash flow in the second period to the gross yield on physical capital and reserves holdings net of gross interest payments on deposits and loans.

The marginal effects of $n_{t+1}$ and $l_{t+1}$ on the bank's objective read (dropping arguments of the $\nu_{t}$ function)

$$
\begin{aligned}
-\left(\nu_{t}(\ldots)-\theta_{t}\right)+\nu_{1, t}(\ldots) \zeta_{t+1}+ & \mathbb{E}_{t}\left[\operatorname{sdf}_{t+1}\left(R_{t+1}^{k}-R_{t+1}^{n}-n_{t+1} R_{t+1}^{n}{ }^{\prime}\left(n_{t+1}\right)\right)\right], \\
& \mathbb{E}_{t}\left[\operatorname{sdf}_{t+1}\left(R_{t+1}^{k}-R_{t+1}^{l}-l_{t+1} R_{t+1}^{l}{ }^{\prime}\left(l_{t+1}\right)\right)\right] .
\end{aligned}
$$

Using the household's Euler equation we can therefore express the first-order conditions with respect to $n_{t+1}$ and $l_{t+1}$ as

$$
\begin{aligned}
-\left(\nu_{t}(\ldots)-\theta_{t}\right)+\nu_{1, t}(\ldots) \zeta_{t+1}+\chi_{t+1}^{n} & \leq n_{t+1} R_{t+1}^{n}{ }^{\prime}\left(n_{t+1}\right) / R_{t+1}^{f}, \quad n_{t+1} \geq 0 \\
\chi_{t+1}^{l} & \leq l_{t+1} R_{t+1}^{l}{ }^{\prime}\left(l_{t+1}\right) / R_{t+1}^{f}, \quad l_{t+1} \geq 0 .
\end{aligned}
$$

The left-hand side of inequality (8) represents the marginal expected profit from deposit issuance, holding the interest rate on deposits constant: Managing the marginal unit of deposits costs $\nu_{t}(\ldots)-\theta_{t}$ and in addition, the marginal unit increases the operating costs for inframarginal units, but it also yields a gain if the deposit liquidity premium is positive, $\chi_{t+1}^{n}>0$. The right-hand side equals the profit loss on inframarginal deposits due to the increase in $R_{t+1}^{n}$ that is triggered by higher deposit issuance. ${ }^{17}$ Deposit issuance is profitable at the margin as long as the left-hand side exceeds the right-hand side.

Inequality (9) relates the marginal expected profit from central bank loans holding the loan interest rate constant, $\chi_{t+1}^{l} \equiv 1-R_{t+1}^{l} / R_{t+1}^{f}$, to the cost increase on inframarginal loans due to more expensive funding. When deposits or central bank loans are strictly

\footnotetext{
${ }^{16}$ Variables $l_{t+1}, r_{t+1}, \zeta_{t+1}, \operatorname{sdf}_{t}, R_{t+1}^{l}, R_{t+1}^{r}, \pi_{1, t}^{b}, \pi_{2, t}^{b}, \theta_{t}$, and $\nu_{t}$ are measurable with respect to information available at date $t$. We do not normalize the typical bank's portfolio positions by the number of banks. That is, we state the conditions as they apply for the banking sector as a whole.

${ }^{17}$ For this increase to be well defined the bank must perceive $m_{t+1}$ to be less than infinitely elastic with respect to $n_{t+1}$. This condition is satisfied, for example, when the central bank targets $m_{t+1}$ or $m_{t+1}$ relative to $n_{t+1}$; it is violated when the central bank targets $R_{t+1}^{m}$ at a level that renders money competitive with deposits.
} 
positive then the inequalities (8) or (9) simplify to

$$
\begin{aligned}
\chi_{t+1}^{n}-\left(\nu_{t}(\ldots)-\theta_{t}-\nu_{1, t}(\ldots) \zeta_{t+1}\right) & =\frac{1}{\eta_{n, t+1}} \frac{R_{t+1}^{n}}{R_{t+1}^{f}}, \\
\chi_{t+1}^{l} & =\frac{1}{\eta_{l, t+1}} \frac{R_{t+1}^{l}}{R_{t+1}^{f}},
\end{aligned}
$$

where $\eta_{n, t+1}$ and $\eta_{l, t+1}$, respectively, denote the elasticity of deposit and loan supply by households and the central bank with respect to $R_{t+1}^{n}$ and $R_{t+1}^{l}$ (cf. Klein, 1971; Monti, 1972).

Finally, turning to reserves, when $n_{t+1}>0$ such that reserves are interior then the corresponding first-order condition reads

$$
-\nu_{1, t}\left(\zeta_{t+1}, \bar{\zeta}_{t+1}\right)=1-\frac{R_{t+1}^{r}}{R_{t+1}^{f}}
$$

Intuitively, the optimal choice of reserves equalizes the gain due to lower operating costs and the loss due to the bank's lower return when the spread on reserves, $\chi_{t+1}^{r} \equiv 1-$ $R_{t+1}^{r} / R_{t+1}^{f}$, is positive. Since in equilibrium $\zeta_{t+1}=\bar{\zeta}_{t+1}$ equation 10 implies a unique mapping from the opportunity costs of holding reserves to the equilibrium reserves-todeposits ratio, which we write as $\zeta_{t+1}=\nu_{1, t}^{-1}\left(-\chi_{t+1}^{r}\right){ }^{18}$

Combining equations (8) and (10) implies that as long as $n_{t+1}>0$,

$$
\chi_{t+1}^{n}-\left(\tilde{\nu}_{t}\left(-\chi_{t+1}^{r}\right)-\theta_{t}\right)=\frac{1}{\eta_{n, t+1}} \frac{R_{t+1}^{n}}{R_{t+1}^{f}},
$$

where we define

$$
\tilde{\nu}_{t}(-\chi) \equiv \nu_{t}\left(\nu_{1, t}^{-1}(-\chi), \nu_{1, t}^{-1}(-\chi)\right)+\chi \nu_{1, t}^{-1}(-\chi) .
$$

Function $\tilde{\nu}_{t}$ summarizes the direct and indirect effect of deposits on the bank's operating costs: A marginal increase in deposit issuance raises the total operating costs not only directly, by $\nu_{t}\left(\zeta_{t+1}, \zeta_{t+1}\right)$, but also indirectly because $\nu_{t}\left(\zeta_{t+1}, \zeta_{t+1}\right)$ increases. The magnitude of these effects is pinned down by the opportunity costs of reserves and the bank's first-order condition for reserves, equation (10).

It sometimes is instructive to consider a reduced form version of the model without the reserves layer. In that version $\nu_{t}$ is exogenous and banks therefore do not hold reserves. Accordingly, $\tilde{\nu}_{t}\left(-\chi_{t+1}^{r}\right)$ is replaced by the exogenous $\nu_{t}$ in that case.

\footnotetext{
${ }^{18}$ By the mean value theorem, for any $\varepsilon>0$ there exists an $\iota$ between 0 and $\varepsilon$ such that $\nu_{1, t}(\zeta+\varepsilon, \zeta+\varepsilon)=$ $\nu_{1, t}(\zeta, \zeta)+\left(\nu_{11, t}(\zeta+\iota, \zeta+\iota)+\nu_{12, t}(\zeta+\iota, \zeta+\iota)\right) \varepsilon$. We claim that $\nu_{11, t}+\nu_{12, t}>0$ such that the function $\nu_{1, t}(\zeta, \zeta)$ is monotonically increasing in $\zeta$ and therefore invertible. Strict convexity of $\nu_{t}$ implies that its Hessian is positive definite such that, in particular, $\nu_{11, t}>0$ and $\nu_{11, t}+2 \nu_{12, t}+\nu_{22, t}>0$. Recall that we assume $\nu_{12, t}=0$ or $\nu_{11, t} \geq \nu_{22, t}$. In the former case the claim is directly established. In the latter case as well because $\nu_{11, t}+\nu_{12, t}>\nu_{11, t}-\left(\nu_{11, t}+\nu_{22, t}\right) / 2>\left(\nu_{11, t}-\nu_{22, t}\right) / 2 \geq 0$.
} 


\section{$2.3 \quad$ Firms}

Firms rent capital, $\kappa_{t}$, and labor, $\ell_{t}$, and produce the output good to maximize profits. They take wages, the rental rate of capital, $R_{t}^{k}-1+\delta$, and the goods price as given; the rental rate reflects the depreciation rate, $\delta .{ }^{19}$ Letting $f_{t}$ denote a neoclassical production function the representative firm solves

$$
\begin{array}{cl}
\max _{\kappa_{t}, \ell_{t}} & \pi_{t}^{f} \\
\text { s.t. } & \pi_{t}^{f}=f_{t}\left(\kappa_{t}, \ell_{t}\right)-\kappa_{t}\left(R_{t}^{k}-1+\delta\right)-w_{t} \ell_{t} .
\end{array}
$$

The first-order conditions read

$$
\begin{aligned}
R_{t}^{k}-1+\delta & =f_{\kappa, t}\left(\kappa_{t}, \ell_{t}\right) \\
w_{t} & =f_{\ell, t}\left(\kappa_{t}, \ell_{t}\right) .
\end{aligned}
$$

Since $f_{t}$ exhibits constant returns to scale and firms are competitive, equilibrium profits will equal zero.

\subsection{Government}

The consolidated government collects taxes, pays subsidies, invests in capital, $k_{t+1}^{g}$, lends to the bank, and issues money and reserves. ${ }^{20}$ The unit resource costs of managing money equal $\mu_{t}$, and the unit resource costs of managing reserves equals $\rho_{t}$. Accordingly, the government budget constraint reads

$$
k_{t+1}^{g}+l_{t+1}-m_{t+1}-r_{t+1}=k_{t}^{g} R_{t}^{k}+l_{t} R_{t}^{l}-m_{t} R_{t}^{m}-r_{t} R_{t}^{r}+\tau_{t}-n_{t+1} \theta_{t}-m_{t+1} \mu_{t}-r_{t+1} \rho_{t} .
$$

\subsection{Market Clearing}

Households inelastically supply labor. Labor and capital market clearing as well as the bank's balance sheet identity and the definition of total profits require

$$
\ell_{t}=1-x_{t}, \quad \kappa_{t}=k_{t}+k_{t}^{g}+n_{t}+l_{t}-r_{t}, \quad \pi_{t}=\pi_{1, t}^{b}+\pi_{2, t}^{b}+\pi_{t}^{f} .
$$

\subsection{Resource Constraint}

Walras' law implies that market clearing on the markets for labor and capital as well as the budget constraints of households, banks, firms, and the government imply market clearing on the market for the output good. Specifically, combining equations (1), (6), (7), (11), 14), and (15) yields the resource constraint

$$
\kappa_{t+1}=f_{t}\left(\kappa_{t}, 1-x_{t}\right)+\kappa_{t}(1-\delta)-c_{t}-m_{t+1} \mu_{t}-n_{t+1} \nu_{t}\left(\zeta_{t+1}, \zeta_{t+1}\right)-r_{t+1} \rho_{t} .
$$

\footnotetext{
${ }^{19}$ Variables $\pi_{t}^{f}, \kappa_{t+1}$ and $\ell_{t}$ are measurable with respect to information available at date $t$.

${ }^{20}$ Variable $k_{t+1}^{g}$ is measurable with respect to information available at date $t$.
} 


\subsection{Policy and Equilibrium}

A policy $\mathcal{P}$ consists of $\left\{\tau_{t}, \theta_{t}\right\}_{t \geq 0} ;\left\{m_{t+1}\right\}_{t \geq 0},\left\{R_{t+1}^{m}\right\}_{t \geq 0}$, or $\left\{\chi_{t+1}^{m}\right\}_{t \geq 0}$ if the central bank issues money and targets its quantity, interest rate, or spread, respectively; a loan supply schedule if the central bank extends loans; as well as $\left\{r_{t+1}\right\}_{t \geq 0},\left\{R_{t+1}^{r}\right\}_{t \geq 0}$, or $\left\{\chi_{t+1}^{r}\right\}_{t \geq 0}$ if the central bank issues reserves and targets their quantity, interest rate, or spread respectively.

We can now define equilibrium:

Definition 1. An equilibrium with means of payment of type $i \in\{m, n\}$ and conditional on policy $\mathcal{P}$ consists of

- a positive allocation, $\left\{c_{t}, x_{t}, k_{t+1}, k_{t+1}^{g}, \kappa_{t+1}, \ell_{t}\right\}_{t \geq 0}$;

- positive money, deposit, and reserve holdings and loans, $\left\{m_{t+1}, n_{t+1}, r_{t+1}, l_{t+1}\right\}_{t \geq 0}$;

- and a positive price (and shadow price) system, $\left\{w_{t}, R_{t}^{k}, R_{t}^{m}, R_{t}^{n}, R_{t+1}^{r}\right\}_{t \geq 0}$,

such that (1)-(8), (10)- (15) (and by implication (16)) are satisfied, and the asset positions as well as the price system are consistent with the policy. If the central bank extends loans then (9) also must be satisfied with equality and the price system also includes the interest rate on loans, $\left\{R_{t+1}^{l}\right\}_{t \geq 0}$.

\subsection{Functional Form Assumptions}

In parts of the analysis we will impose the following functional form assumptions:

Assumption 1. Preferences and the deposit operating costs, respectively, satisfy

$$
\begin{aligned}
u\left(c_{t}, z_{t+1}, x_{t}\right) & =\left((1-\vartheta) c_{t}^{1-\psi}+\vartheta z_{t+1}^{1-\psi}\right)^{\frac{1-\sigma}{1-\psi}}(1-\sigma)^{-1} v\left(x_{t}\right) \\
\nu_{t}\left(\zeta_{t+1}, \bar{\zeta}_{t+1}\right) & =\phi_{1, t} \zeta_{t+1}^{1-\varphi}+\phi_{2, t} \bar{\zeta}_{t+1}^{1-\varphi}
\end{aligned}
$$

where $\vartheta, \psi \in(0,1) ; \sigma>0, \neq 1 ; \phi_{1, t}, \phi_{2, t} \geq 0 ; \varphi \geq 1$. Function $v$ either is strictly increasing and concave or constant.

Note that the preference specification allows for a balanced growth path along which consumption, wages, and asset holdings grow at the same rate while interest rates, spreads, labor supply and leisure remain constant (King et al., 1988). The elasticity of substitution between $c_{t}$ and $z_{t+1}$ is given by $\psi^{-1}$. For $v^{\prime}\left(x_{t}\right)=0$ the model reduces to a specification without leisure. For $\varphi=1$, the model variant without a reserves layer results.

\section{General Equilibrium}

In this section we discuss positive implications of the model. 


\subsection{Model Solution}

We start with an example and show how the model can easily be solved. We focus on the empirically most relevant case of a monetary arrangement with deposits and no money (CBDC) and impose assumption 1. In appendix A we present detailed derivations and discuss other constellations, including the case with money and different central bank targets.

The key steps in the derivation are as follows: First, we show that the household holds deposits in proportion to consumption and depending on $\chi_{t+1}^{n}$. Second, we solve the bank's problem given the demand for real balances by the household, the spread on reserves, the subsidy, as well as the shocks impinging on the interbank payment system (reflected in the function $\nu_{t}$ ). This yields closed form solutions that relate $\chi_{t+1}^{n}$ and $\zeta_{t+1}$ to $\chi_{t+1}^{r}, \theta_{t}, \phi_{1, t}, \phi_{2, t}$ as well as other parameters. Finally, we combine these results to find the three comprehensive equilibrium conditions

$$
\begin{aligned}
c_{t}^{-\sigma} v\left(x_{t}\right) & =\beta \mathbb{E}_{t}\left[\left(1-\delta+f_{\kappa, t+1}\left(\kappa_{t+1}, 1-x_{t+1}\right)\right) c_{t+1}^{-\sigma} v\left(x_{t+1}\right) \frac{\Omega_{t+1}^{c}\left(\chi_{t+2}^{r}, \theta_{t+1}\right)}{\Omega_{t}^{c}\left(\chi_{t+1}^{r}, \theta_{t}\right)}\right], \\
\frac{c_{t}^{1-\sigma}}{1-\sigma} v^{\prime}\left(x_{t}\right) & =c_{t}^{-\sigma} v\left(x_{t}\right) f_{\ell, t}\left(\kappa_{t}, 1-x_{t}\right) \frac{\Omega_{t}^{c}\left(\chi_{t+1}^{r}, \theta_{t}\right)}{\Omega_{t}^{x}\left(\chi_{t+1}^{r}, \theta_{t}\right)}, \\
\kappa_{t+1} & =f_{t}\left(\kappa_{t}, 1-x_{t}\right)+\kappa_{t}(1-\delta)-c_{t} \Omega_{t}^{r c}\left(\chi_{t+1}^{r}, \theta_{t}\right) .
\end{aligned}
$$

This system of equilibrium conditions (plus a transversality condition) corresponds to the conditions in the basic real business cycle (RBC) model (King et al., 1988) with household preferences given by $u\left(c_{t}, x_{t}\right)=\left(c_{t}^{1-\sigma}-1\right) /(1-\sigma) v\left(x_{t}\right)$, augmented by three "pseudo wedges:" A term in the intertemporal first-order condition, $\Omega_{t+1}^{c}\left(\chi_{t+2}^{r}, \theta_{t+1}\right) / \Omega_{t}^{c}\left(\chi_{t+1}^{r}, \theta_{t}\right)$; a term in the intratemporal first-order condition, $\Omega_{t}^{c}\left(\chi_{t+1}^{r}, \theta_{t}\right) / \Omega_{t}^{x}\left(\chi_{t+1}^{r}, \theta_{t}\right)$; and a term multiplying consumption in the resource constraint, $\Omega_{t}^{r c}\left(\chi_{t+1}^{r}, \theta_{t}\right)$. These three terms are determined by the functions $\Omega_{t}^{i}\left(\chi_{t+1}^{r}, \theta_{t}\right), i \in\{c, x, r c\}$ which in turn depend on policy, $\left(\chi_{t+1}^{r}, \theta_{t}\right)$, and the payment technology shocks. Conditional on the shocks and policy instruments the model thus can be solved exactly like the RBC model.

The $\Omega_{t}^{i}\left(\chi_{t+1}^{r}, \theta_{t}\right)$ terms can directly be compared with wedges in an RBC model due to labor-income taxes at rate $\tau_{t}^{x}$, consumption taxes at rate $\tau_{t}^{c}$, as well as government consumption, $g_{t}$. More specifically, the RBC model with taxes and government consumption immediately results once we replace $\Omega_{t}^{c}\left(\chi_{t+1}^{r}, \theta_{t}\right)$ by $\left(1+\tau_{t}^{c}\right)^{-1} ; \Omega_{t}^{x}\left(\chi_{t+1}^{r}, \theta_{t}\right)$ by $\left(1-\tau_{t}^{x}\right)^{-1}$; and $\Omega_{t}^{r c}\left(\chi_{t+1}^{r}, \theta_{t}\right)$ by $\left(g_{t}+c_{t}\right) / c_{t}$. Unlike tax wedges the pseudo wedges in our monetary framework should not be interpreted as efficiency wedges, however. They simply represent the additional terms relative to a frictionless RBC model that deposits, reserves, and banks introduce into the equilibrium conditions.

For $\vartheta \rightarrow 0, \Omega_{t}^{i}\left(\chi_{t+1}^{r}, \theta_{t}\right) \rightarrow 1$ (see the appendix) and the model collapses to the RBC model. Along a balanced growth path with constant policy the intertemporal pseudo wedge also equals on ${ }^{21}$ but the intratemporal pseudo wedge and the term in the resource constraint differ from unity. Specifically, the pseudo wedge in the first-order condition

\footnotetext{
${ }^{21}$ The same result follows if utility is separable between consumption and real balances, $\psi=\sigma$.
} 
characterizing the labor-leisure tradeoff is given by

$$
\frac{\Omega_{t}^{x}\left(\chi_{t+1}^{r}, \theta_{t}\right)}{\Omega_{t}^{c}\left(\chi_{t+1}^{r}, \theta_{t}\right)}=1+\left(\frac{\vartheta}{1-\vartheta}\right)^{\frac{1}{\psi}}\left(\tilde{\chi}_{t+1}^{n}\left(\chi_{t+1}^{r}, \theta_{t}\right)\right)^{1-\frac{1}{\psi}}>1,
$$

where $\tilde{\chi}_{t+1}^{n}\left(\chi_{t+1}^{r}, \theta_{t}\right)$ represents the equilibrium deposit spread as a function of policy and shocks (see the appendix). Compared with the RBC model, the presence of payments $(\vartheta>0)$ thus has similar effects on the consumption-leisure tradeoff as the tax wedge due to a distorting labor-income tax that varies with policy.

Since our framework with deposits, bank market power, and reserves directly maps into the dominant macro workhorse model, it lends itself to a straightforward analysis by policy institutions using established methods. This remains the case when additional elements are introduced. For example, it is trivial to include tax distortions. As the derivations in the appendix make clear a distorting tax on labor income would simply introduce an additional (exogenous) tax wedge in the consumption-leisure first-order condition. The same holds true in the other model variants discussed in the appendix.

\subsection{Real Allocation and Monetary Policy Nonneutrality}

In a steady state the marginal utility of consumption is constant and monetary policy therefore does not affect the capital-labor ratio, which is pinned down by the Euler equation for capital. ${ }^{22}$ This result holds independently of assumption 1 as long as the consumption-to-real-balances ratio is stationary ${ }^{23}$ Along a balanced growth path monetary policy does not affect the capital-labor ratio either when it enters the expression for the marginal utility of consumption in equilibrium separably, as it does under assumption 1 (see the equilibrium conditions given earlier).

In contrast, the payment system and monetary policy do affect the consumptionleisure ratio along a balanced growth path (and during the transition). We have already established this for the case where assumption 1 holds. The nonneutrality arises because real balances affect the marginal utilities of consumption and leisure to a different extent. ${ }^{24}$ From the resource constraint the payment system and monetary policy then also affect output and its composition.

Being a "real" model the framework exhibits monetary neutrality: If equilibrium is consistent with a given amount of nominal balances and a given price level then it is also consistent with nominal balances and prices that are scaled by a common positive factor; such scaling leaves real interest rates and liquidity premia unaffected. Whether the model also exhibits superneutrality depends on one's assumption about how inflation is passed through to interest rates. Under the standard assumption that real risk-free rates are not affected by anticipated inflation while real rates on money or deposits fall (because they are fixed or inelastic), the liquidity premia $\chi^{m}$ and $\chi^{n}$ rise together with inflation implying

\footnotetext{
${ }^{22}$ If real balances constituted an argument of the production function (with real balances and capital as substitutes) the model would feature a "Tobin effect" (Tobin, 1965; Fischer, 1972).

${ }^{23}$ See Walsh (2017, 2.2.1) for a discussion of steady states with nonstationary consumption-to-realbalances ratios.

${ }^{24}$ That is, because $\Omega_{t}^{c}\left(\chi_{t+1}^{r}, \theta_{t}\right) \neq \Omega_{t}^{x}\left(\chi_{t+1}^{r}, \theta_{t}\right)$.
} 
reduced demand for means of payment. As discussed above, inflation differentially affects the marginal utilities of consumption and leisure in this case, and thus the allocation 25

\subsection{Liquidity Premia}

Under assumption 1 the liquidity premium on deposits (in an equilibrium with deposits) is given by

$$
\tilde{\chi}_{t+1}^{n}\left(\chi_{t+1}^{r}, \theta_{t}\right)=\frac{\left(\phi_{1, t} \varphi+\phi_{2, t}\right)\left(\frac{\chi_{t+1}^{r}}{\phi_{1, t}(\varphi-1)}\right)^{1-\frac{1}{\varphi}}-\theta_{t}}{1-\psi}, \quad \varphi \geq 1, \psi \in(0,1)
$$

(see appendix A). Accordingly, a higher (lower) liquidity premium on reserves drives up (down) the liquidity premium on deposits. In contrast, a higher bank subsidy reduces the liquidity premium and raises the equilibrium interest rate on deposits.

Higher external costs due to limited reserve holdings (higher $\phi_{2, t}$ ) unambiguously raise the liquidity premium on deposits. Intuitively, a higher $\phi_{2, t}$ raises the costs for banks but banks shift these costs partly to households. More surprisingly, higher internal costs due to limited reserve holdings (higher $\phi_{1, t}$ ) have an ambiguous effect on $\chi_{t+1}^{n}$ : The effect is positive (negative) when $\phi_{2, t}$ or $\varphi$ are small (large) relative to $\phi_{1, t}$. Intuitively, a higher $\phi_{1, t}$ induces banks to hold more reserves relative to deposits, driving up the costs of reserve holdings but reducing the internal and external direct costs of managing the payment system which are reflected in the function $\nu_{t}$.

We state this last finding as a proposition:

Proposition 1. With external benefits of reserve holdings, higher internal benefits can reduce the liquidity premium on deposits (raise the deposit interest rate). Under assumption 1 this is the case when $\phi_{1, t}+\phi_{2, t}\left(\varphi^{-1}-1\right)<0$.

Proof. Differentiation of $\tilde{\chi}_{t+1}^{n}\left(\chi_{t+1}^{r}, \theta_{t}\right)$ with respect to $\phi_{1, t}$ yields

$$
\frac{\partial \tilde{\chi}_{t+1}^{n}\left(\chi_{t+1}^{r}, \theta_{t}\right)}{\partial \phi_{1, t}} \propto \phi_{1, t}+\phi_{2, t}\left(\varphi^{-1}-1\right)
$$

\subsection{Reversal Rate}

While low interest rates reduce funding costs they can also pose problems for banks; below a "reversal rate" the disadvantages may outweigh the advantages ${ }^{26}$ Let $R$ denote

\footnotetext{
${ }^{25}$ See Walsh $(2017,2.4 .2)$ for a discussion of nonsuperneutrality.

${ }^{26}$ See, for example, Brunnermeier and Koby (2018). In a model with cash the effective lower bound constitutes a critical threshold for the nominal interest rate. It is straightforward to analyze such an effective lower bound in the model once one introduces inflation. Absent cash in the model, however, such an analysis would be somewhat unfounded.
} 
the gross reversal rate and suppose that policy makers aim at keeping banks' preferred deposit rate above the reversal rate:

$$
R_{t+1}^{f}\left(1-\tilde{\chi}_{t+1}^{n}\left(\chi_{t+1}^{r}, \theta_{t}\right)\right) \geq R
$$

For a given risk-free interest rate this can be achieved by raising the interest rate on reserves or bank subsidies.

Under assumption 1 a marginal increase in the subsidy, which imposes fiscal costs $n_{t+1}$, relaxes the constraint by

$$
R_{t+1}^{f} /(1-\psi)
$$

In contrast, a marginal increase in the interest rate on reserves, which imposes fiscal costs $n_{t+1} \zeta_{t+1}=n_{t+1}\left(\frac{\chi_{t+1}^{r}}{\phi_{1, t}(\varphi-1)}\right)^{-\frac{1}{\varphi}}$, relaxes the constraint by

$$
R_{t+1}^{f} \frac{\left(1-\frac{1}{\varphi}\right)\left(\phi_{1, t} \varphi+\phi_{2, t}\right)\left(\frac{\chi_{t+1}^{r}}{\phi_{1, t}(\varphi-1)}\right)^{-\frac{1}{\varphi}}}{(1-\psi) \phi_{1, t}(\varphi-1) R_{t+1}^{f}}=\frac{\left(\phi_{1, t} \varphi+\phi_{2, t}\right)\left(\frac{\chi_{t+1}^{r}}{\phi_{1, t}(\varphi-1)}\right)^{-\frac{1}{\varphi}}}{\varphi(1-\psi) \phi_{1, t}}
$$

Accordingly, the cost-benefit ratios of higher bank subsidies and interest on reserves, respectively, are given by

$$
\frac{n_{t+1}(1-\psi)}{R_{t+1}^{f}} \text { versus } \frac{n_{t+1} \varphi(1-\psi) \phi_{1, t}}{\phi_{1, t} \varphi+\phi_{2, t}} .
$$

We thus have the following result:

Proposition 2. Under assumption 1, a reversal rate constraint can be relaxed more cheaply by paying interest on reserves rather than subsidies if and only if

$$
\frac{\phi_{1, t} \varphi+\phi_{2, t}}{\phi_{1, t} \varphi}>R_{t+1}^{f}
$$

that is, if external benefits of reserves are high or the risk-free rate low.

Intuitively, with external benefits of reserves holdings an increase in the interest rate on reserves lowers the costs for banks both directly and, as a consequence of the optimal portfolio adjustments of other financial institutions, indirectly. In contrast, a higher subsidy only has a direct effect on bank costs. As a consequence, higher interest on reserves raises the deposit rate more strongly than bank subsidies, per dollar of government expenditure.

\section{Optimality}

In this section we discuss normative implications of the model. We allow for deposits, reserves, and money to circulate in parallel. 


\subsection{Social Planner Allocation}

The social planner solves

$$
\begin{gathered}
\max _{\left\{c_{t}, x_{t}, \kappa_{t+1}, m_{t+1}, n_{t+1}, r_{t+1}\right\}_{t \geq 0}} \sum_{t=0}^{\infty} \beta^{t} \mathbb{E}_{0}\left[u\left(c_{t}, z_{t+1}, x_{t}\right)\right] \\
\text { s.t. } \quad \kappa_{t+1}=f_{t}\left(\kappa_{t}, 1-x_{t}\right)+\kappa_{t}(1-\delta)-c_{t}-m_{t+1} \mu_{t}-n_{t+1} \nu_{t}\left(\zeta_{t+1}, \zeta_{t+1}\right)-r_{t+1} \rho_{t}, \\
\quad \kappa_{t+1}, m_{t+1}, n_{t+1}, r_{t+1} \geq 0 .
\end{gathered}
$$

The optimality conditions for capital, consumption, and leisure are standard. They yield the usual first-order conditions, which also hold in the decentralized equilibrium (see equations (2), (3), (12), (13), and (15)),

$$
\begin{aligned}
& u_{c}\left(c_{t}, z_{t+1}, x_{t}\right)=\beta \mathbb{E}_{t}\left[\left(1-\delta+f_{\kappa, t+1}\left(\kappa_{t+1}, 1-x_{t+1}\right)\right) u_{c}\left(c_{t+1}, z_{t+2}, x_{t+1}\right)\right], \\
& u_{x}\left(c_{t}, z_{t+1}, x_{t}\right)=u_{c}\left(c_{t}, z_{t+1}, x_{t}\right) f_{\ell, t}\left(\kappa_{t}, 1-x_{t}\right) .
\end{aligned}
$$

The optimality condition for reserves reads

$$
\begin{aligned}
\nu_{1, t}\left(\zeta_{t+1}, \zeta_{t+1}\right)+\nu_{2, t}\left(\zeta_{t+1}, \zeta_{t+1}\right)+\rho_{t} & =0 \text { if } n_{t+1}>0 \\
r_{t+1} & =0 \text { otherwise. }
\end{aligned}
$$

Intuitively, when the planner relies on deposits then it issues reserves up to the point where the cost reduction for deposit payments, $\nu_{1, t}\left(\zeta_{t+1}, \zeta_{t+1}\right)+\nu_{2, t}\left(\zeta_{t+1}, \zeta_{t+1}\right)$, is balanced by the costs of managing the marginal reserve unit, $\rho_{t}$. If reserves exert an externality, i.e., if a bank's reserves lower the operating costs of other banks such that $\nu_{2, t}\left(\zeta_{t+1}, \zeta_{t+1}\right) \neq 0$, then the planner takes this into account. This contrasts with the decentralized equilibrium where a bank only internalizes its own cost reduction from reserve holdings, see equation (10). Strict convexity of the function $\nu_{t}$ implies a unique mapping from $\rho_{t}$ to the optimal choice of reserves, conditional on $n_{t+1}{ }^{27}$

Finally, the first-order conditions for money and deposits yield the optimality condition

$$
u_{z}\left(c_{t}, z_{t+1}, x_{t}\right)=u_{c}\left(c_{t}, z_{t+1}, x_{t}\right) \min \left[\mu_{t} / \lambda_{t}, \nu_{t}\left(\zeta_{t+1}^{\star}, \zeta_{t+1}^{\star}\right)+\zeta_{t+1}^{\star} \rho_{t}\right]
$$

where we use the condition for reserves derived above ${ }^{28}$ The variable $\zeta_{t+1}^{\star}$ denotes the reserves-to-deposits ratio chosen by the social planner when restricted to use deposits rather than money.

To interpret equation $(\overline{\mathrm{SP}})$, consider first the case where reserves do not affect the operating costs of deposit based payments such that $\nu_{t}$ is exogenous (the model variant without the reserves layer). In this case, equation $(\mathrm{SP})$ reduces to

$$
u_{z}\left(c_{t}, z_{t+1}, x_{t}\right)=u_{c}\left(c_{t}, z_{t+1}, x_{t}\right) \min \left[\mu_{t} / \lambda_{t}, \nu_{t}\right] .
$$

\footnotetext{
${ }^{27}$ By the mean value theorem, for any $\varepsilon>0$ there exists an $\iota$ between 0 and $\varepsilon$ such that $\nu_{1, t}(\zeta+\varepsilon, \zeta+$ $\varepsilon)+\nu_{2, t}(\zeta+\varepsilon, \zeta+\varepsilon)=\nu_{1, t}(\zeta, \zeta)+\nu_{2, t}(\zeta, \zeta)+\left(\nu_{11, t}(\zeta+\iota, \zeta+\iota)+2 \nu_{12, t}(\zeta+\iota, \zeta+\iota)+\nu_{22, t}(\zeta+\iota, \zeta+\iota)\right) \varepsilon$. Strict convexity of $\nu_{t}$ implies that its Hessian is positive definite such that, in particular, $\nu_{11, t}+2 \nu_{12, t}+\nu_{22, t}>0$. This implies that the function $\nu_{1, t}(\zeta, \zeta)+\nu_{2, t}(\zeta, \zeta)$ is monotonically increasing in $\zeta$ and therefore invertible.

${ }^{28}$ The resource costs of a marginal deposit equal $\nu_{t}\left(\zeta_{t+1}, \zeta_{t+1}\right)-\zeta_{t+1}\left(\nu_{1, t}\left(\zeta_{t+1}, \zeta_{t+1}\right)+\nu_{2, t}\left(\zeta_{t+1}, \zeta_{t+1}\right)\right)$.
} 
This has two implications. One concerns the quantity of liquidity that is optimally provided, the other its source. As for the quantity, the social planner satiates the household with real balances up to the point where the marginal benefit of real balances equals the marginal resource costs, both expressed in utility terms. This is just a variant of the Friedman (1969) rule which, in its more common form, abstracts from resource costs of managing liquidity.

As for the source of liquidity, the optimality condition implies that the planner generically provides only one means of payment. When $\lambda_{t}$ strictly exceeds (falls short of) $\mu_{t} / \nu_{t}$ then the first best involves money but no deposits (vice versa). Only when $\mu_{t} / \nu_{t}=\lambda_{t}$ when the relative resource costs of money and deposits and their relative liquidity benefits happen to coincide - is the planner indifferent between the two payment instruments.

Consider next the case where reserves do affect the operating costs of deposit based payments such that $\nu_{t}$ is a function of $\zeta_{t+1}$ (the baseline model). In this case, equation (SP) holds and the optimal allocation still has the two properties emphasized before. The only difference to the case with exogenous $\nu_{t}$ is that the planner compares the resource costs of managing money (accounting for its liquidity benefits), $\mu_{t} / \lambda_{t}$, and the costs of managing deposits and reserves when the reserves-to-deposits ratio is chosen to minimize costs.

Summarizing:

Proposition 3. The social planner provides the means of payment with the lowest resource costs per unit of effective liquidity. It satiates the household with real balances up to the point where the marginal benefit of real balances equals the marginal resource costs.

The result that the social planner generically relies on a single means of payment follows from our assumption that money and deposits enter additively in effective real balances. In a more general setting with a nonlinear aggregation of the two sources of liquidity it would typically be optimal to hold a portfolio including both money and deposits.29 The satiation result, in contrast, would also hold in such a more general setting.

\subsection{Ramsey Policy}

In contrast to the social planner, the Ramsey government controls the allocation and liquidity only indirectly, by way of choosing policy instruments that support an equilibrium. We show next that the Ramsey government nevertheless can implement the social planner allocation, even in the absence of central bank loans, $\left\{l_{t+1}\right\}_{t \geq 0}=\mathbf{0}$. That is, we show that there exists a policy $\mathcal{P}$ subject to $\left\{l_{t+1}\right\}_{t \geq 0}=\mathbf{0}$ which supports an equilibrium with the social planner allocation 30 Since any equilibrium satisfies the social planner's Euler equations for capital and leisure as well as the resource constraint the Ramsey policy implements the first best if the first-best quantities for money, deposits, and reserves

\footnotetext{
${ }^{29} \mathrm{~A}$ similar qualification applies with respect to the cost structure we have assumed. If both money and deposits entered as arguments of $\mu_{t}$ and/or $\nu_{t}$ the planner might use both means of payment.

${ }^{30}$ Inequality $(9)$ is not an equilibrium condition in this case.
} 
satisfy the equilibrium conditions for money and deposit holdings by households as well as banks' optimality conditions for deposits and reserves.

Suppose first that money is the more efficient means of payment, $\mu_{t} / \lambda_{t} \leq \nu_{t}\left(\zeta_{t+1}^{\star}, \zeta_{t+1}^{\star}\right)+$ $\zeta_{t+1}^{\star} \rho_{t}$, such that the social planner does not engage in deposit creation. The Ramsey government can replicate the first-best outcome in this case by issuing the efficient amount of money, charging the liquidity premium on money

$$
\chi_{t+1}^{m \star} \equiv \mu_{t},
$$

and pricing banks out of the market. Equation (RA-1) follows directly from equations (4) and $(\overline{\mathrm{SP}})$. To see that banks can be priced out of the market, recall from equation (5) that households only hold deposits if the interest rate, $R_{t+1}^{n}$, weakly exceeds $R_{t+1}^{f}-$ $\left(R_{t+1}^{f}-R_{t+1}^{m}\right) / \lambda_{t}$. With $\chi_{t+1}^{m}=\mu_{t}\left(\right.$ or $\left.R_{t+1}^{f}-R_{t+1}^{m}=\mu_{t} R_{t+1}^{f}\right)$ this would require $R_{t+1}^{n} \geq$ $R_{t+1}^{f}\left(1-\mu_{t} / \lambda_{t}\right)$. But paying such a high interest rate would generate losses for banks if the government set subsidies to zero and increased the liquidity premium on reserves sufficiently, which it can ${ }^{31}$

Suppose next that deposits are more efficient such that the social planner does not issue money. In this case a tradeoff arises for the Ramsey government. On the one hand, issuing money helps to check bank market power since the deposit spread reflects total liquidity, not only the quantity of deposits. On the other hand, money provides liquidity at a higher resource cost. As it turns out, the deposit subsidy, $\theta_{t}$, helps to resolve this tension.

To see this, consider first a relaxed program without the bank's optimality condition for deposits, inequality (8). In this relaxed program the Ramsey government can replicate the first best by issuing no money but the efficient amount of deposits, charging the liquidity premium on deposits

$$
\chi_{t+1}^{n \star} \equiv \nu_{t}\left(\zeta_{t+1}^{\star}, \zeta_{t+1}^{\star}\right)+\zeta_{t+1}^{\star} \rho_{t}
$$

and setting the liquidity premium on reserves to

$$
\chi_{t+1}^{r \star} \equiv-\nu_{1, t}\left(\zeta_{t+1}^{\star}, \zeta_{t+1}^{\star}\right) .
$$

Equation (RA-2 follows again directly from equations (4) and (SP). The liquidity premium on reserves in (RA-3) follows from equation (10) and the planner's optimal choice of reserves: The premium must induce banks to select the first-best reserves-to-deposits ratio even when there are external effects that the banks do not internalize. We conclude that the Ramsey allocation in the relaxed program coincides with the social planner allocation 32

Consider next the full Ramsey program including equation (8) or (8a). The key question is how restrictive this equilibrium condition is: Can banks be induced to charge

\footnotetext{
${ }^{31}$ In the model variant without a reserves layer where $\nu_{t}$ is exogenous the same argument applies: Without government subsidies, paying a "competitive" interest rate on deposits would generate losses for banks.

${ }^{32}$ In the model variant without a reserves layer the right-hand side of equation $\mathrm{RA}-2$ is replaced by $\nu_{t}$. Moreover, the Ramsey government need not target the reserves-to-deposits ratio but it also has one less instrument, $\chi_{t+1}^{r}$, at its disposal. As a consequence, the first best can still be implemented.
} 
the liquidity premium on deposits given in (RA-2 - and thus to demand the first-best quantity of deposits - when the central bank charges the liquidity premium on reserves given in (RA-3)? They can, when the subsidy $\theta_{t}$ in equation (8a) takes the value, $\theta_{t}^{\star}$, which renders the equation evaluated at $\chi_{t+1}^{n \star}$ and $\chi_{t+1}^{r \star}$ consistent with the first-best deposit demand 33

From equation (8a) this subsidy satisfies

$$
\theta_{t}^{\star} \equiv \frac{1}{\eta_{n, t+1}} \frac{R_{t+1}^{n \star}}{R_{t+1}^{f \star}}-\chi_{t+1}^{n \star}+\tilde{\nu}_{t}\left(-\chi_{t+1}^{r \star}\right)
$$

where $R_{t+1}^{f \star}$ is pinned down by the first-best allocation and $R_{t+1}^{n \star} \equiv R_{t+1}^{f \star}\left(1-\chi_{t+1}^{n \star}\right)$. Using $(\mathrm{RA}-2)$ and $(\mathrm{RA}-3)$ this can be expressed as

$$
\theta_{t}^{\star}=\frac{1}{\eta_{n, t+1}} \frac{R_{t+1}^{n \star}}{R_{t+1}^{f \star}}+\zeta_{t+1}^{\star} \nu_{2, t}\left(\zeta_{t+1}^{\star}, \zeta_{t+1}^{\star}\right) .
$$

The optimal subsidy has two components which reflect the two frictions, lack of competition and externalities. The effect of lack of competition on the subsidy is positive; the higher the supply elasticity of deposits, the smaller this effect. The effect of the (positive) externality, in contrast, is negative. Intuitively, with external benefits from reserves the Ramsey government subsidizes reserves by issuing them at a reduced liquidity premium, $\chi_{t+1}^{r \star}$, and sterilizes the consequences of this intervention on the deposit margin by means of a negative subsidy on deposits.

Summarizing:

Proposition 4. The Ramsey policy implements the first best independently of whether the social planner relies on money or deposits. In the former case the Ramsey policy is characterized by equation (RA-1). In the latter case it satisfies equations (RA-2)-(RA-4); deposits may be taxed or subsidized.

Of course, proposition 4 also applies when exogenous restrictions rule out either money or deposits such that a priori only a single retail means of payment is available. More importantly, proposition 4 generalizes to settings with nonlinear aggregation of liquidity (endogenous $\lambda_{t}$ ). The Ramsey policy can implement the social planner outcome even in such general settings because the three policy instruments $\chi_{t+1}^{m}, \chi_{t+1}^{r}$, and $\theta_{t}$ suffice to control the amount of liquidity, its composition between deposits and money, and banks' willingness to issue deposits.

\subsection{Policy Rules}

Under the Ramsey policy liquidity premia only respond to developments in the payment sector, not in the "real" economy: $\chi_{t+1}^{m \star}$ varies with $\mu_{t}$ while $\chi_{t+1}^{n \star}$ and $\chi_{t+1}^{r \star}$ depend on

\footnotetext{
${ }^{33}$ While the first best is a global maximum in the social planner's program the first-best deposit quantity need not correspond to a global optimum in the bank's program subject to the subsidy. We neglect this issue for now and restrict ourselves to a "first-order approach." When we impose the functional form assumptions the problem does not arise, see appendix B
} 
$\rho_{t}$ as well as the cost function $\nu_{t}$. In contrast, the subsidy $\theta_{t}^{\star}$ also reflects shocks to preferences and firm technology, through their effects on the allocation $\left(R_{t+1}^{f \star}\right){ }^{34}$ Focusing on the more interesting case with deposits and reserves we can derive further results by imposing assumption 1. The optimal reserves-to-deposits ratio, liquidity premia, and subsidy, respectively, then satisfy (see appendix B)

$$
\begin{aligned}
\zeta_{t+1}^{\star} & =\left(\frac{\left(\phi_{1, t}+\phi_{2, t}\right)(\varphi-1)}{\rho_{t}}\right)^{\frac{1}{\varphi}}, \\
\chi_{t+1}^{r \star} & =\rho_{t} \frac{\phi_{1, t}}{\phi_{1, t}+\phi_{2, t}} \leq \rho_{t}, \\
\chi_{t+1}^{n \star} & =\left(\frac{\rho_{t}}{\left(\phi_{1, t}+\phi_{2, t}\right)(\varphi-1)}\right)^{1-\frac{1}{\varphi}}\left(\phi_{1, t}+\phi_{2, t}\right) \varphi, \\
\theta_{t}^{\star} & =\left(\frac{\rho_{t}}{\left(\phi_{1, t}+\phi_{2, t}\right)(\varphi-1)}\right)^{1-\frac{1}{\varphi}}\left(\psi\left(\phi_{1, t}+\phi_{2, t}\right) \varphi-\phi_{2, t}(\varphi-1)\right) .
\end{aligned}
$$

The optimal reserves-to-deposits ratio increases in the extent to which reserves lower the costs of the deposit based payment system, both internally $\left(\phi_{1, t}\right)$ or externally $\left(\phi_{2, t}\right)$. The optimal ratio falls with the central bank's resource costs of reserves operations, $\rho_{t}$.

The optimal spread on reserves reflects the operating costs of the reserves layer, $\rho_{t}$. When banks' reserve holdings generate externalities $\left(\phi_{2, t}>0\right)$ then the Ramsey government subsidizes reserve holdings, $\chi_{t+1}^{r \star}<\rho_{t}$, in order to induce banks to internalize the external effects. The expression for $\chi_{t+1}^{r \star}$ can be read as a Taylor (1993)-type interest rate rule. It says that the optimal gross interest rate on reserves, $R_{t+1}^{r \star}$, should respond to the risk-free interest rate and to the determinants of $\chi_{t+1}^{r \star}$, namely $\rho_{t}$ and $\phi_{2, t}$ :

$$
R_{t+1}^{r \star}=R_{t+1}^{f}\left(1-\rho_{t} \frac{\phi_{1, t}}{\phi_{1, t}+\phi_{2, t}}\right) \text {. }
$$

That is, $R_{t+1}^{r \star}$ moves one-to-one with $R_{t+1}^{f}$ and at risk-free interest rates near zero $\left(R_{t+1}^{f} \approx\right.$ 1) the optimal interest rate on reserves equals $-\rho_{t} \phi_{1, t} /\left(\phi_{1, t}+\phi_{2, t}\right)$.

The optimal liquidity premium on deposits reflects the social costs of operating the deposit payment system. When reserves are costless to provide $\left(\rho_{t}=0\right)$ then the optimal liquidity premium equals zero. When reserves operations require resources $\left(\rho_{t}>0\right)$, in contrast, then the structure of the function $\nu_{t}$ matters for the liquidity premium. When reserves are more important for the payment system, either internally or externally, then the liquidity premium rises; this effect is weaker when $\varphi$ is large such that the elasticity of $\nu_{t}$ with respect to the reserves-to-deposits ratio is strongly negative.

Finally, the sign of the optimal subsidy is ambiguous as already stated in proposition 4 . Lack of competition $(\psi)$ affects the subsidy positively, externalities $\left(\phi_{2, t}\right)$ negatively. More specifically, we have the following result:

\footnotetext{
${ }^{34}$ This holds true unless $R_{t+1}^{n \star} / R_{t+1}^{f \star} / \eta_{n, t+1}$ is orthogonal to $R_{t+1}^{f \star}$.
} 
Proposition 5. Under assumption 1, the optimal subsidy in an economy with deposits is strictly negative when

$$
\frac{\phi_{2, t}}{\phi_{1, t}+\phi_{2, t}}>\psi \frac{\varphi}{\varphi-1}
$$

and strictly positive when the reverse inequality holds.

When reserves do not generate externalities $\left(\phi_{2, t}=0\right)$ then the subsidy is positive and in fact, $\theta_{t}^{\star}=\psi \chi_{t+1}^{n \star}$; in the limit where consumption and effective real balances are perfect substitutes $(\psi \rightarrow 0)$ the subsidy equals zero in this case.

Optimal policy in the model variant without a reserves layer follows when we let $\varphi \rightarrow 1$ : The optimal reserves-to-deposits ratio satisfies $\zeta_{t+1}^{\star}=0$ in this case; the optimal liquidity premium on deposits satisfies $\chi_{t+1}^{n \star}=\phi_{1, t}+\phi_{2, t}$; and the optimal subsidy satisfies $\theta_{t}^{\star}=\psi\left(\phi_{1, t}+\phi_{2, t}\right)=\psi \chi_{t+1}^{n \star}$.

\section{Equivalence}

In this section we establish an equivalence class of monetary arrangements with different compositions of real balances. Subsequently, we exploit the equivalence result to assess implicit subsidies to the banking system. In appendix D we establish a second equivalence result that relates changes in taxes and the ownership structure of capital.

\subsection{Equivalence of Monetary Arrangements}

The main equivalence result, which extends results in Brunnermeier and Niepelt (2019) and Niepelt $(2018 ; 2020)$, establishes the "irrelevance" of the composition of real balances 35 It implies that, as long as the private and public sector are equally efficient in operating payment systems, a change in the composition of real balances in the household sector need not affect the equilibrium allocation. For the central bank can always assure that a portfolio shift from deposits into money leaves equilibrium consumption, capital accumulation, and the price system unchanged.

Private and public means of payment thus are substitutes in general equilibrium as long as the central bank intervenes appropriately. If it does, portfolio shifts out of deposits and into money (CBDC) do not endanger bank funding nor do they undermine bank intermediation. Importantly, and as will become clear, these results do not require any assumptions regarding a specific monetary friction; that is, they hold independently of whether the money-in-the-utility-function specification used so far or any other monetary friction is assumed.

The following condition stipulates that the resource costs per effective unit of real balances are identical for the central bank and banks:

\footnotetext{
35 Brunnermeier and Niepelt (2019) consider the case without reserves nor resource costs of providing liquidity. Substitutability between money and deposits guarantees "liquidity neutrality" in the terminology of Brunnermeier and Niepelt (2019).
} 
Condition 1. $\mu_{t} / \lambda_{t}=\nu_{t}\left(\zeta_{t+1}, \zeta_{t+1}\right)+\zeta_{t+1} \rho_{t}$ where $\zeta_{t+1}$ denotes the equilibrium reservesto-deposits ratio.

Consider a reduction in deposit holdings at date $t$, complemented by a (not necessarily equal sized) increase in money holdings also at date $t$. We have the following result, which is formally stated and proved in appendix $\mathrm{C}$;

Proposition 6. Suppose condition 1 holds. Consider a policy and equilibrium with deposits, reserves, and no central bank loan. There exists another policy and equilibrium with fewer deposits and reserves, more money, a central bank loan, a different ownership structure of capital, and otherwise the same allocation and price system 36 The central bank loan carries the interest rate

$$
R_{t+1}^{l}=\frac{R_{t+1}^{n}+\left(\nu_{t}\left(\zeta_{t+1}, \zeta_{t+1}\right)-\theta_{t}\right) R_{t+1}^{f}-\zeta_{t+1} R_{t+1}^{r}}{1-\zeta_{t+1}} .
$$

The logic underlying the proposition is simple: When households supply fewer deposits to banks but hold more money with the central bank then the central bank can pass this additional funding through to the banking sector as loans. Bank intermediation need not change. With an appropriate choice of loan supply schedule the central bank can replicate the effective choice set of banks before the intervention. Subject to this loan supply schedule the initial equilibrium prices and allocation and the modified portfolios constitute an equilibrium. The effects on the real economy are confined to portfolio changes. Establishing these results requires an analysis of the budget and choice sets of banks, households, firms, and the government, see appendix C. As emphasized before this analysis is orthogonal to a specific monetary friction, for instance money in the utility function.

According to proposition 6 the loan interest rate, $R_{t+1}^{l}$, which supports the equivalent portfolio positions, reflects the (old and new) equilibrium reserves-to-deposits ratio, $\zeta_{t+1}$. There are three reasons for this dependence; they relate both to the quantity of bank funding and its price. First, one dollar of deposit funding only results in $1-\zeta_{t+1}$ dollars of net bank funding because the bank invests $\zeta_{t+1}$ dollars in reserves. This explains the $1-\zeta_{t+1}$ term in the denominator of the expression for the loan rate. Second, the cost of deposit sourced funding depends on the share of deposits that is invested in reserves. This explains the term $-\zeta_{t+1} R_{t+1}^{r}$ in the numerator. And third, the reserves-to-deposits ratio affects the operating costs, $\nu_{t}\left(\zeta_{t+1}, \zeta_{t+1}\right)$.

Two further remarks are in order. First, in the model variant without a reserves layer where $\nu_{t}$ is exogenous the proposition applies subject to the obvious modifications. In particular, the condition for equivalence is given by $\mu_{t} / \lambda_{t}=\nu_{t}$ in that case. Second, since the first-best reserves-to-deposits ratio, $\zeta_{t+1}^{\star}$, may differ from the ratio in equilibrium the condition for the equivalence of money and deposits, condition 1, need not coincide with the condition under which the social planner is indifferent between the two means of payment, $\mu_{t} / \lambda_{t}=\nu_{t}\left(\zeta_{t+1}^{\star}, \zeta_{t+1}^{\star}\right)+\zeta_{t+1}^{\star} \rho_{t} \cdot 37$ That is, it is conceivable that the introduction

\footnotetext{
${ }^{36}$ The new policy may also include state contingent taxes whose market value equals zero.

${ }^{37}$ However, in the model variant without a reserves layer the two conditions coincide.
} 
of money (CBDC) is "irrelevant" as far as equilibrium outcomes are concerned although the social planner or the Ramsey government strictly prefers money over deposits or vice versa.

\subsection{Bank Profits and Lender-of-Last-Resort Support}

Banks earn profits by providing liquidity. But do banks themselves create this liquidity? Or do they benefit from beliefs held by the public (and upheld by instruments such as deposit insurance and lender-of-last-resort facilities) that these claims are implicitly guaranteed by the central bank? If one accepts the latter view then it is natural to ask how valuable the implicit guarantees for banks are, that is, how highly banks are implicitly subsidized. If one accepts the view that banks themselves create the value associated with liquidity then it is equally natural to ask how high that value is. Proposition 6 allows to answer these questions.

To price the liquidity created by deposits it suffices to price the marginal unit. Assuming that condition 1 -identical resource costs of deposit and money liquidity servicesholds at the margin we conclude from proposition 6 that an equilibrium allocation where households transact using deposits (be it an optimal allocation or not) can alternatively be supported by an arrangement in which the central bank extends a loan in the amount of $n_{t+1}\left(1-\zeta_{t+1}\right)$ as a substitute for the deposit funding $n_{t+1}$ net of reserve holdings $n_{t+1} \zeta_{t+1}$. Moreover, according to proposition 6, the gross interest rate on the loan in this equivalent arrangement equals

$$
R_{t+1}^{l}=R_{t+1}^{r}+\frac{R_{t+1}^{n}-R_{t+1}^{r}}{1-\zeta_{t+1}}+\frac{\left(\nu_{t}\left(\zeta_{t+1}, \zeta_{t+1}\right)-\theta_{t}\right) R_{t+1}^{f}}{1-\zeta_{t+1}} .
$$

If the central bank or markets funded banks at the "illiquid" market interest rate, bank funding would cost $R_{t+1}^{f}$ per unit. In an arrangement with deposits, or equivalently with a central bank loan priced at the equivalent loan rate, however, bank funding costs $R_{t+1}^{l}$ per unit. The total funding cost reduction that banks enjoy, expressed as a share of GDP, thus amounts to

$$
\mathrm{fcr}_{t} \equiv \frac{R_{t+1}^{f}-R_{t+1}^{l}}{R_{t+1}^{f}} \frac{n_{t+1}\left(1-\zeta_{t+1}\right)}{\mathrm{GDP}_{t}} .
$$

In the following we provide estimates for $\mathrm{fcr}_{t}$.

Figure 2 displays quarterly U.S. time series data for the (inflation adjusted) gross reserve rate, $R_{t+1}^{r}$, the gross risk-free rate, $R_{t+1}^{f}$, and the gross deposit rate, $R_{t+1}^{n}$; the data spans the interval 1999q1-2017q4. We use FRED data for the interest rate on reserves and Kurlat's (2019) estimates of the risk-free, "illiquid" interest rate as well as the deposit rate. Appendix E contains detailed information.

The figure shows that the (inflation adjusted) interest rate on reserves fluctuates in a band between -3 and 0 percent while the risk-free rate varies between -2 and 4 percent. After 2010, the two rates nearly coincide. The deposit rate typically lies between the reserve rate and the risk-free rate, except towards the end of the sample when it falls 


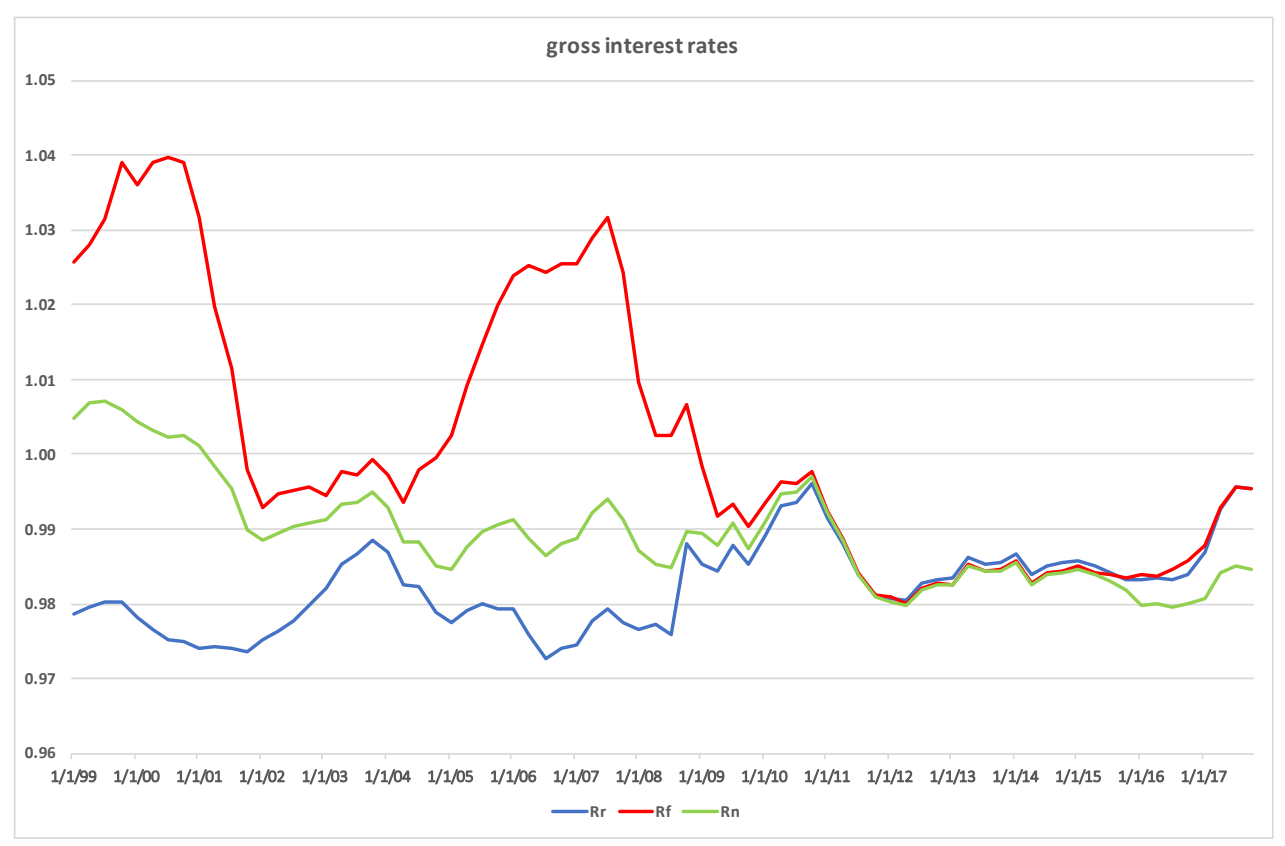

Figure 2: Gross interest rates.

below the other two rates. Between 2009 and 2015, the spreads between the three rates nearly disappear.

Figure 3 displays quarterly time series data for the reserves-to-deposits ratio, $\zeta_{t+1}$, over the same period. We use FRED data as well as data constructed by Lucas and Nicolini (2015) for reserves and deposits. For the deposit series, we use two alternative measures. The first, indicated by [a], is the sum of checkable and savings deposits. The second, indicated by [b], is the sum of checkable deposits and money market deposit accounts as specified by Lucas and Nicolini (2015). Appendix E contains more information.

Independently of the exact measure, the reserves-to-deposits ratio strongly increases in mid 2008, from a very low level (at which it had been since the early 1980s). It reaches a maximum of 30 or 45 percent, depending on the measure, in mid 2014 and falls back to 20 or 30 percent by the end of 2017 .

Figure 4 displays estimates of the implied loan rate, $R_{t+1}^{l}$, and funding cost reduction for banks, fcr f $_{t}$ under the assumption that $\nu_{t}\left(\zeta_{t+1}, \zeta_{t+1}\right)-\theta_{t}=0.01^{38}$ (Below, we present alternative results based on a model implied measure of $\nu_{t}\left(\zeta_{t+1}, \zeta_{t+1}\right)-\theta_{t}$. $)$ The two estimates of $R_{t+1}^{l}$ and $\mathrm{fcr}_{t}$ correspond to the two measures of the reserves-to-deposits ratio; the differences are minor.

The equivalent central bank loan interest rate displayed in the top panel falls from nearly 2 percent early in the sample to -0.5 percent towards the end, with a temporary increase to 1 percent in late 2010. Intuitively, prior to 2009 when $\zeta_{t+1}$ is very small the equivalent loan rate roughly equals $R_{t+1}^{n}+0.01$ as $R_{t+1}^{f} \approx 1$. In $2009,1-\zeta_{t+1}$ increases

\footnotetext{
${ }^{38}$ Lucas and Nicolini (2015, p. 57) assume that banks' costs of check processing equals 1 percent of GDP. Philippon (2015) estimates that the costs of financial intermediation equal 1.5 to 2 percent of intermediated assets. The ratio of deposits to GDP equals one third to one half.
} 


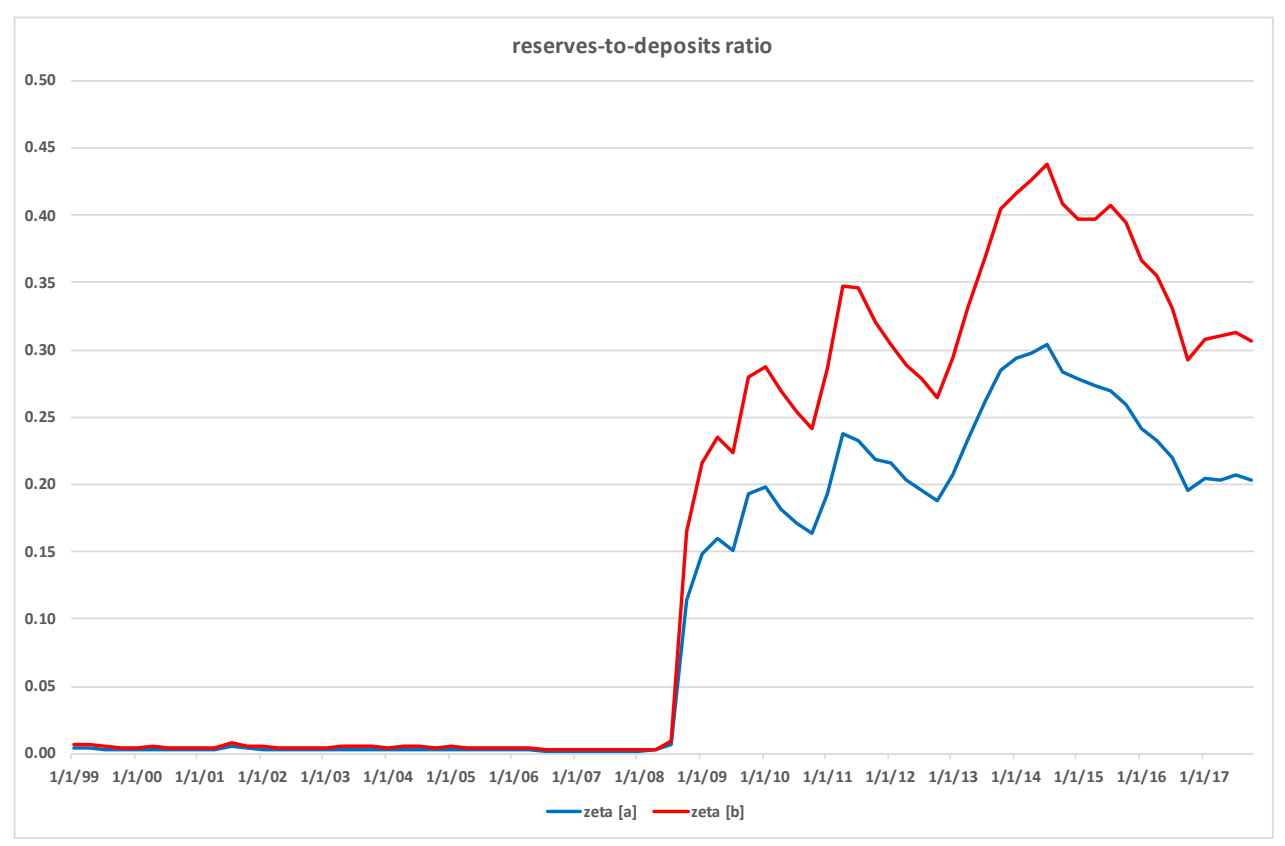

Figure 3: Two measures of the reserves-to-deposits ratio.

and this pushes $R_{t+1}^{l}$ up: One dollar of net funding now requires more than one dollar of deposit funding and this increases the equivalent loan rate as long as $R_{t+1}^{r}<R_{t+1}^{n}$. Between 2009 and 2015, $R_{t+1}^{r} \approx R_{t+1}^{n}$ and the equivalent loan rate therefore roughly follows $R_{t+1}^{r}+0.01 /\left(1-\zeta_{t+1}\right)$. After 2015 the deposit rate falls short of the reserve rate and this contributes negatively to the equivalent loan rate.

The bottom panel of figure 4 illustrates the implied funding cost reduction for banks. The times series fluctuates between 0.8 and -0.7 percent of GDP, reflecting two major drivers. On the one hand, the long-term downward trend in $R_{t+1}^{f}-R_{t+1}^{l}$ and its fluctuations. And on the other hand, the U-shaped path of $1-\zeta_{t+1}$ after 2008 and an increasing deposits-to-GDP ratio. Early in the sample the equivalent central bank loan reduces banks' funding costs by roughly 0.5 percent of GDP because the risk-free rate exceeds the equivalent loan rate. Subsequently, when the interest rate differential $R_{t+1}^{f}-R_{t+1}^{l}$ changes from positive to negative, $\mathrm{fcr}_{t}$ becomes slightly negative before approaching 0.8 percent in 2006. In early 2009 the interest rate differential turns negative again, pushing fcr for $_{t}$ another eight years into negative territory. Only in 2017 does the interest rate differential turn positive again as $R_{t+1}^{f}$ increases more sharply than $R_{t+1}^{n}$ and $R_{t+1}^{l}$; accordingly, fcr $\mathrm{f}_{t}$ becomes positive as well.

Figure 5 displays estimates of the implied loan rate and funding cost reduction under the alternative assumption that banks optimally set the deposit rate. Under assumption 1 the first-order condition of banks implies $\nu_{t}\left(\zeta_{t+1}, \zeta_{t+1}\right)-\theta_{t}=(1-\psi) \chi_{t+1}^{n}-\zeta_{t+1} \chi_{t+1}^{r}$ (see appendix A). We assume that $\psi=0.5$ and based on this assumption, back out $\nu_{t}\left(\zeta_{t+1}, \zeta_{t+1}\right)-\theta_{t}$. The implied equivalent loan rate again displays a downward trend, falling by roughly 3 percent over the sample period and interrupted by a hump before the financial crisis (that is, earlier than under the previous calibration). The implied funding 
cost reduction varies between 0 and 0.5 percent of GDP. It is always positive because now, $R_{t+1}^{f}$ always exceeds $R_{t+1}^{l} 39$

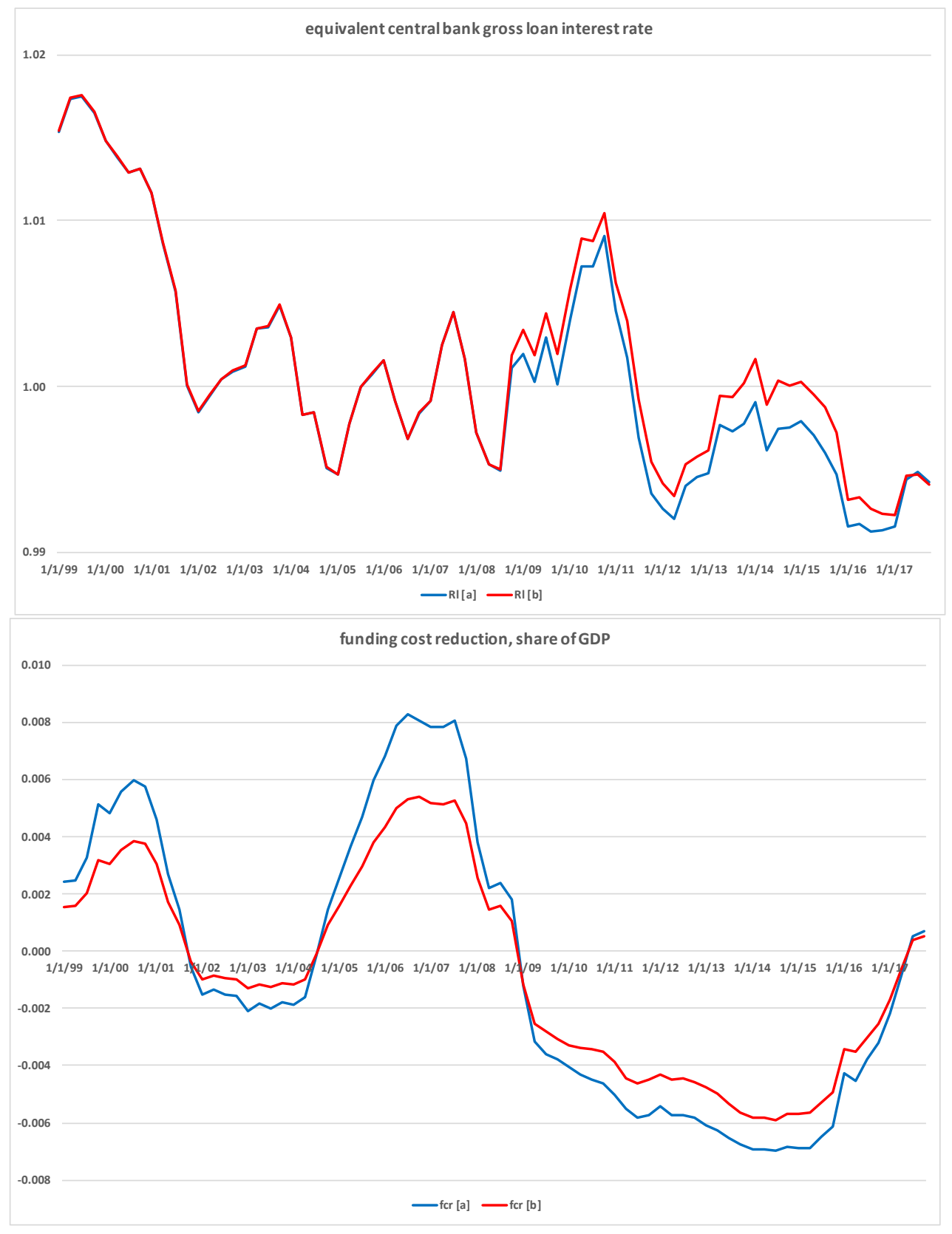

Figure 4: Two measures of the equivalent central bank gross loan interest rate (top) and banks' funding cost reduction (bottom) under the assumption that $\nu_{t}-\theta_{t}=0.01$.

\footnotetext{
${ }^{39}$ With $\psi=0.5$ and, in the second half of the sample, $\zeta_{t+1} \approx 0.3$ we have $R_{t=1}^{l} \approx R_{t+1}^{r}+\left(R_{t+1}^{n}-\right.$ $\left.R_{t+1}^{r}+0.5\left(R_{t+1}^{f}-R_{t+1}^{n}\right)-0.3\left(R_{t+1}^{f}-R_{t+1}^{r}\right)\right) / 0.7=\left(0.2 R_{t+1}^{f}+0.5 R_{t+1}^{n}\right) / 0.7$ which is smaller than $R_{t+1}^{f}$ in the data.
} 


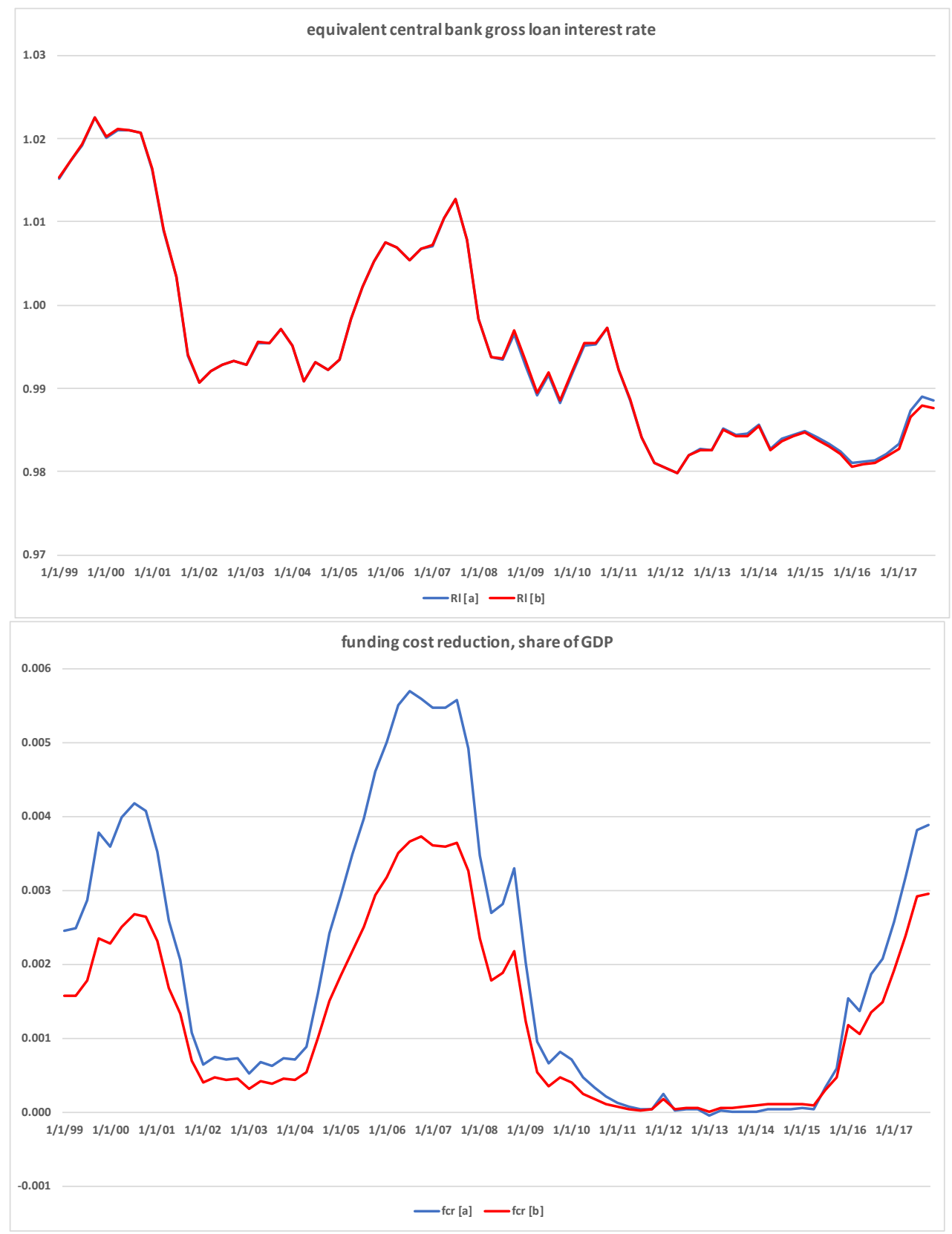

Figure 5: Two measures of the equivalent central bank gross loan interest rate (top) and banks' funding cost reduction (bottom) under the assumption that the optimality condition of banks holds and $\psi=0.5$.

In conclusion, we find that under either calibration assumption the U.S. banking sector benefited from a funding cost reduction of roughly 0.4 to 0.8 percent of GDP just before and around the financial crisis but did not benefit from such a cost reduction, or even bore additional funding costs, once financial markets calmed. These numbers compare with NIPA data for financial sector profits on the order of 3 percent of GDP prior to the financial crisis, negative profits during the crisis, and 2 to 3 percent of GDP after 
the financial crisis. During the financial crisis the low equivalent loan rate relative to the risk-free interest rate appears to have been an important factor to contribute towards stabilizing U.S. banks' profits.

\section{Politics}

Recall that the central bank's profit generated by policy choices at date $t$ equals

$$
m_{t+1}\left(\mathbb{E}_{t}\left[\operatorname{sdf}_{t+1}\left(R_{t+1}^{k}-R_{t+1}^{m}\right)\right]-\mu_{t}\right)+n_{t+1}\left\{\zeta_{t+1}\left(\mathbb{E}_{t}\left[\operatorname{sdf}_{t+1}\left(R_{t+1}^{k}-R_{t+1}^{r}\right)\right]-\rho_{t}\right)-\theta_{t}\right\},
$$

where we abstract from central bank loans. Equivalently, the profit is given by

$$
m_{t+1}\left(\chi_{t+1}^{m}-\mu_{t}\right)+n_{t+1}\left\{\zeta_{t+1}\left(\chi_{t+1}^{r}-\rho_{t}\right)-\theta_{t}\right\} .
$$

When the central bank issues money and banks do not issue deposits, $n_{t+1}=0$, the optimal monetary policy implements the Friedman rule for money according to which the liquidity premium on money equals the operating costs of running a money based payment system, see equation (RA-1). As a consequence, the central bank balances its budget, at least in present value.

When the central bank does not issue money, $m_{t+1}=0$, but banks issue deposits, in contrast, then two structural effects undermine budget balance under the optimal policy: First, the central bank makes losses on its reserves management operations if reserves exert a positive externality. This follows from equation (RA-3), which implies

$$
\chi_{t+1}^{r \star}-\rho_{t}=\chi_{t+1}^{r \star}+\nu_{1, t}\left(\zeta_{t+1}^{\star}, \zeta_{t+1}^{\star}\right)+\nu_{2, t}\left(\zeta_{t+1}^{\star}, \zeta_{t+1}^{\star}\right)=\nu_{2, t}\left(\zeta_{t+1}^{\star}, \zeta_{t+1}^{\star}\right)<0 .
$$

Second, the central bank or the treasury pay a (positive or negative) subsidy to induce banks to charge the first-best liquidity premium on deposits, see equation (RA-4). Summing the two effects yields, from equations $(\overline{\mathrm{RA}-3})$ and $(\mathrm{RA}-4)$,

$$
\zeta_{t+1}^{\star}\left(\chi_{t+1}^{r \star}-\rho_{t}\right)-\theta_{t}^{\star}=-\frac{1}{\eta_{n, t+1}} \frac{R_{t+1}^{n \star}}{R_{t+1}^{f \star}}<0,
$$

that is, the budgetary impact under the optimal policy is unambiguously negative unless banks are competitive ${ }^{40}$

To understand this result, recall that the subsidy has two components. The first addresses the distortion due to lack of competition, and the second sterilizes the effect of the central bank's artificially low spread on reserves when reserves generate positive externalities. Since the second component of the subsidy exactly balances the fiscal effects of the artificially cheap reserves the net budgetary impact fully reflects the subsidy component that addresses lack of competition.

We summarize the discussion in the following proposition:

\footnotetext{
${ }^{40}$ Under assumption 1 the budgetary impact per unit of deposit satisfies

$$
-\left(\frac{\rho_{t}}{\left(\phi_{1, t}+\phi_{2, t}\right)(\varphi-1)}\right)^{1-\frac{1}{\varphi}} \psi\left(\phi_{1, t}+\phi_{2, t}\right) \varphi .
$$
}


Proposition 7. Under the optimal policy, the government must fiscally support a deposit based payment system unless banks are competitive. This is not the case with a money based payment system.

We conclude the section with some speculative conclusions from proposition 7. One conclusion relates to the political support for the introduction of CBDC. When conditon 1 holds such that deposits can be replaced by CBDC without changing the allocation one might expect political support for the introduction of CBDC since the fiscal costs of a twotiered payment system exceed those in a money based system. In the model considered in this paper this result would immediately follow when taxes were assumed to cause distortions. In a richer framework with heterogeneous groups of households the political support for CBDC would also depend on the distribution of tax burdens, the ownership structure of banks, and the aggregation of preferences in the political process.

Another conclusion relates to central bank independence which is widely seen as a key pillar of stability oriented monetary policies. One factor contributing to this independence is a structural central bank surplus. A central bank with structural deficits that regularly requires fiscal support from the treasury (because the treasury does not directly fund bank subsidies itself) is in a weaker position to defend its independence than a central bank that generates surpluses ${ }^{41}$ From this perspective the model suggests that a money (CBDC) based payment system would better safeguard central bank independence ${ }^{42}$

\section{Conclusion}

We have analyzed monetary policy in a two-tiered monetary system with noncompetitive banks that issue deposits and a central bank that issues reserves and a retail CBDC. Monies differ with respect to operating costs and liquidity. We have mapped the framework into a baseline business cycle model with "pseudo wedges" and derived optimal Taylor (1993)-type policy rules: Spreads satisfy modified Friedman rules and deposits must be taxed or subsidized.

We have also generalized the Brunnermeier and Niepelt (2019) result on the macro irrelevance of CBDC and we have shown that a bank based payment system requires higher taxes. This could strengthen the political support for the introduction of CBDC and it could imply that central bank independence is under greater threat in a deposit rather than CBDC based payment system. We have used the equivalence result to assess the funding cost reduction for U.S. banks due to the fact that they can issue deposits. The model implied annual funding cost reduction amounts to up to 0.8 percent of GDP during the period 1999-2017.

Our framework offers a tractable workhorse model to study monetary policies that are concerned with the payment system and financial stability. It naturally lends itself

\footnotetext{
${ }^{41}$ See Del Negro and Sims (2015) and Hall and Reis $(2015)$ for possible implications of large central bank balance sheets on the need for treasury support for central banks.

${ }^{42}$ There are other political economy considerations that the analysis abstracts from. For example, a money (CBDC) based arrangement necessitates a larger central bank balance sheet which arguably invites more lobbying and political interference. See Niepelt (2020) for a discussion.
} 
to many extensions. One such extension could be to integrate price rigidities and consequently, policy motives related to demand stabilization. Another natural extension could be to integrate heterogeneity and political economy considerations, as discussed above. We leave these extensions for future research.

\section{A General Equilibrium under Assumption 1}

Households Let $\mathcal{A}_{t} \equiv(1-\vartheta) c_{t}^{1-\psi}+\vartheta z_{t+1}^{1-\psi}$ such that the marginal utilities of consumption and real balances, respectively, are given by

$$
\begin{aligned}
& u_{c}\left(c_{t}, z_{t+1}, x_{t}\right)=(1-\vartheta) \mathcal{A}_{t}^{\frac{1-\sigma}{1-\psi}-1} c_{t}^{-\psi} v\left(x_{t}\right), \\
& u_{z}\left(c_{t}, z_{t+1}, x_{t}\right)=\vartheta \mathcal{A}_{t}^{\frac{1-\sigma}{1-\psi}-1} z_{t+1}^{-\psi} v\left(x_{t}\right) .
\end{aligned}
$$

Firms Wages and the return on capital, respectively, satisfy

$$
w_{t}=f_{\ell, t}\left(\kappa_{t}, 1-x_{t}\right), \quad R_{t}^{k}=1-\delta+f_{\kappa, t}\left(\kappa_{t}, 1-x_{t}\right) .
$$

\section{A.1 Case With Deposits}

Consider first the case with deposits, $n_{t+1}>0$.

Households The Euler equation for real balances, equation (4), then reduces to

$$
\frac{\vartheta z_{t+1}^{-\psi}}{(1-\vartheta) c_{t}^{-\psi}}=\chi_{t+1}^{n} \text { or } z_{t+1}=c_{t}\left(\frac{\vartheta}{1-\vartheta} \frac{1}{\chi_{t+1}^{n}}\right)^{\frac{1}{\psi}} \text {. }
$$

The marginal utility with respect to leisure and consumption, respectively, therefore equals

$$
\begin{aligned}
& \left.\frac{\mathcal{A}_{t}^{\frac{1-\sigma}{1-\psi}}}{1-\sigma} v^{\prime}\left(x_{t}\right)\right|_{\text {国 }}=\frac{c_{t}^{1-\sigma}}{1-\sigma}(1-\vartheta)^{\frac{1-\sigma}{1-\psi}}\left(1+\left(\frac{\vartheta}{1-\vartheta}\right)^{\frac{1}{\psi}}\left(\chi_{t+1}^{n}\right)^{1-\frac{1}{\psi}}\right)^{\frac{1-\sigma}{1-\psi}} v^{\prime}\left(x_{t}\right), \\
& \left.(1-\vartheta) \mathcal{A}_{t}^{\frac{1-\sigma}{1-\psi}-1} c_{t}^{-\psi} v\left(x_{t}\right)\right|_{\text {国 }}=c_{t}^{-\sigma}(1-\vartheta)^{\frac{1-\sigma}{1-\psi}}\left(1+\left(\frac{\vartheta}{1-\vartheta}\right)^{\frac{1}{\psi}}\left(\chi_{t+1}^{n}\right)^{1-\frac{1}{\psi}}\right)^{\frac{\psi-\sigma}{1-\psi}} v\left(x_{t}\right) .
\end{aligned}
$$

Banks If the central bank targets $\chi_{t+1}^{m}$ and both money and deposits circulate then $\chi_{t+1}^{n}$ is pinned down by equation (5).

In the following we consider the more interesting case where the central bank targets quantities (possibly $m_{t+1}=0$ ) such that the spread on deposits reflects bank market power. To derive the bank's optimal demand for deposits conditional on the optimal choice of reserves, an instance of equation (8a), suppose first that the central bank directly targets the money supply, $m_{t+1}$. Equation (4) then yields

$$
n_{t+1}=c_{t}\left(\frac{\vartheta}{1-\vartheta} \frac{1}{\chi_{t+1}^{n}}\right)^{\frac{1}{\psi}}-\lambda_{t} m_{t+1} \Rightarrow \eta_{n, t+1} \equiv \frac{n_{t+1}{ }^{\prime}\left(R_{t+1}^{n}\right) R_{t+1}^{n}}{n_{t+1}\left(R_{t+1}^{n}\right)}=\frac{1}{\psi} \frac{R_{t+1}^{n}}{R_{t+1}^{f}-R_{t+1}^{n}} \frac{1}{\xi_{t+1}}
$$


where $\xi_{t+1} \equiv n_{t+1} / z_{t+1}$ denotes the share of deposits in effective real balances. Accordingly, the bank's optimality condition reduces to

$$
\chi_{t+1}^{n}=\frac{\tilde{\nu}_{t}\left(-\chi_{t+1}^{r}\right)-\theta_{t}}{1-\psi \xi_{t+1}} .
$$

Suppose next that the central bank targets $\xi_{t+1}$. We then have

$$
n_{t+1}=\xi_{t+1} c_{t}\left(\frac{\vartheta}{1-\vartheta} \frac{1}{\chi_{t+1}^{n}}\right)^{\frac{1}{\psi}} \Rightarrow \eta_{n, t+1}=\frac{1}{\psi} \frac{R_{t+1}^{n}}{R_{t+1}^{f}-R_{t+1}^{n}}
$$

and the bank's optimality condition reduces to

$$
\chi_{t+1}^{n}=\frac{\tilde{\nu}_{t}\left(-\chi_{t+1}^{r}\right)-\theta_{t}}{1-\psi} .
$$

In a monetary arrangement without money $\left(m_{t+1}=0\right.$ and $\left.\xi_{t+1}=1\right)$ the two cases collapse to one.

The bank's optimality condition for reserves, equation (10), implies

$$
-\phi_{1, t}(1-\varphi) \zeta_{t+1}^{-\varphi}=\chi_{t+1}^{r} \Rightarrow \zeta_{t+1}=\left(\frac{\phi_{1, t}(\varphi-1)}{\chi_{t+1}^{r}}\right)^{\frac{1}{\varphi}}
$$

Accordingly, in equilibrium, $\nu_{t}\left(\zeta_{t+1}, \zeta_{t+1}\right)$ equals

$$
\left(\phi_{1, t}+\phi_{2, t}\right)\left(\frac{\phi_{1, t}(\varphi-1)}{\chi_{t+1}^{r}}\right)^{\frac{1-\varphi}{\varphi}}
$$

and $\tilde{\nu}_{t}\left(-\chi_{t+1}^{r}\right)$ is given by

$$
\left(\phi_{1, t}+\phi_{2, t}\right)\left(\frac{\phi_{1, t}(\varphi-1)}{\chi_{t+1}^{r}}\right)^{\frac{1-\varphi}{\varphi}}+\chi_{t+1}^{r}\left(\frac{\phi_{1, t}(\varphi-1)}{\chi_{t+1}^{r}}\right)^{\frac{1}{\varphi}}=\left(\phi_{1, t} \varphi+\phi_{2, t}\right)\left(\frac{\chi_{t+1}^{r}}{\phi_{1, t}(\varphi-1)}\right)^{1-\frac{1}{\varphi}} .
$$

Combined Equilibrium Conditions Consider the case with $m_{t+1}=0$ and define

$$
\begin{aligned}
\tilde{\chi}_{t+1}^{n}\left(\chi_{t+1}^{r}, \theta_{t}\right) \equiv & \frac{\tilde{\nu}_{t}\left(-\chi_{t+1}^{r}\right)-\theta_{t}}{1-\psi} \\
& \text { s.t. } \tilde{\nu}_{t}\left(-\chi_{t+1}^{r}\right)=\left(\phi_{1, t} \varphi+\phi_{2, t}\right)\left(\frac{\chi_{t+1}^{r}}{\phi_{1, t}(\varphi-1)}\right)^{1-\frac{1}{\varphi}}, \\
\Omega_{t}^{x}\left(\chi_{t+1}^{r}, \theta_{t}\right) \equiv & (1-\vartheta)^{\frac{1-\sigma}{1-\psi}}\left(1+\left(\frac{\vartheta}{1-\vartheta}\right)^{\frac{1}{\psi}}\left(\tilde{\chi}_{t+1}^{n}\left(\chi_{t+1}^{r}, \theta_{t}\right)\right)^{1-\frac{1}{\psi}}\right)^{\frac{1-\sigma}{1-\psi}}, \\
\Omega_{t}^{c}\left(\chi_{t+1}^{r}, \theta_{t}\right) \equiv & (1-\vartheta)^{\frac{1-\sigma}{1-\psi}}\left(1+\left(\frac{\vartheta}{1-\vartheta}\right)^{\frac{1}{\psi}}\left(\tilde{\chi}_{t+1}^{n}\left(\chi_{t+1}^{r}, \theta_{t}\right)\right)^{1-\frac{1}{\psi}}\right)^{\frac{\psi-\sigma}{1-\psi}} .
\end{aligned}
$$


The household's optimality conditions for capital and leisure, equations (2) and (3), conditional on optimal real balances holdings as well as bank and firm choices can then be written as

$$
\begin{aligned}
c_{t}^{-\sigma} v\left(x_{t}\right) \Omega_{t}^{c}\left(\chi_{t+1}^{r}, \theta_{t}\right) & =\beta \mathbb{E}_{t}\left[R_{t+1}^{k} c_{t+1}^{-\sigma} v\left(x_{t+1}\right) \Omega_{t+1}^{c}\left(\chi_{t+2}^{r}, \theta_{t+1}\right)\right], \\
\frac{c_{t}^{1-\sigma}}{1-\sigma} v^{\prime}\left(x_{t}\right) \Omega_{t}^{x}\left(\chi_{t+1}^{r}, \theta_{t}\right) & =c_{t}^{-\sigma} v\left(x_{t}\right) \Omega_{t}^{c}\left(\chi_{t+1}^{r}, \theta_{t}\right) w_{t}
\end{aligned}
$$

subject to the firm optimality conditions.

The third equilibrium condition is given by the resource constraint (with $m_{t+1}=0$ ) subject to optimal real balances holdings as well as bank and firm choices. This can be written as

$$
\begin{aligned}
& \kappa_{t+1}=f_{t}\left(\kappa_{t}, 1-x_{t}\right)+\kappa_{t}(1-\delta)-c_{t}-n_{t+1} \nu_{t}\left(\zeta_{t+1}, \zeta_{t+1}\right)-r_{t+1} \rho_{t} \\
& =f_{t}\left(\kappa_{t}, 1-x_{t}\right)+\kappa_{t}(1-\delta)-c_{t}-n_{t+1}\left(\nu_{t}\left(\zeta_{t+1}, \zeta_{t+1}\right)+\zeta_{t+1} \rho_{t}\right) \\
& =f_{t}\left(\kappa_{t}, 1-x_{t}\right)+\kappa_{t}(1-\delta)-c_{t} \Omega_{t}^{r c}\left(\chi_{t+1}^{r}, \theta_{t}\right) \text {, } \\
& \Omega_{t}^{r c}\left(\chi_{t+1}^{r}, \theta_{t}\right) \equiv 1+\left(\frac{\vartheta}{1-\vartheta} \frac{1}{\tilde{\chi}_{t+1}^{n}\left(\chi_{t+1}^{r}, \theta_{t}\right)}\right)^{\frac{1}{\psi}}\left(\nu_{t}\left(\zeta_{t+1}, \zeta_{t+1}\right)+\zeta_{t+1} \rho_{t}\right) \\
& \text { s.t. } \nu_{t}\left(\zeta_{t+1}, \zeta_{t+1}\right)=\left(\phi_{1, t}+\phi_{2, t}\right)\left(\frac{\phi_{1, t}(\varphi-1)}{\chi_{t+1}^{r}}\right)^{\frac{1-\varphi}{\varphi}} \text {, } \\
& \zeta_{t+1}=\left(\frac{\phi_{1, t}(\varphi-1)}{\chi_{t+1}^{r}}\right)^{\frac{1}{\varphi}}
\end{aligned}
$$

\section{A.2 Case Without Deposits}

Consider next the case without deposits, $m_{t+1}>0$ and $n_{t+1}=0$.

Households The Euler equation for money, equation (4), reduces to

$$
\lambda_{t} \frac{\vartheta\left(\lambda_{t} m_{t+1}\right)^{-\psi}}{(1-\vartheta) c_{t}^{-\psi}}=\chi_{t+1}^{m} \quad \text { or } \quad z_{t+1}=\lambda_{t} m_{t+1}=c_{t}\left(\frac{\vartheta}{1-\vartheta} \frac{\lambda_{t}}{\chi_{t+1}^{m}}\right)^{\frac{1}{\psi}}
$$

The marginal utility with respect to leisure and consumption, respectively, therefore equals

$$
\begin{aligned}
& \left.\frac{\mathcal{A}_{t}^{\frac{1-\sigma}{1-\psi}}}{1-\sigma} v^{\prime}\left(x_{t}\right)\right|_{\left.\underline{\underline{1^{\prime}}}\right\rangle}=\frac{c_{t}^{1-\sigma}}{1-\sigma}(1-\vartheta)^{\frac{1-\sigma}{1-\psi}}\left(1+\left(\frac{\vartheta}{1-\vartheta}\right)^{\frac{1}{\psi}}\left(\frac{\chi_{t+1}^{m}}{\lambda_{t}}\right)^{1-\frac{1}{\psi}}\right)^{\frac{1-\sigma}{1-\psi}} v^{\prime}\left(x_{t}\right), \\
& \left.(1-\vartheta) \mathcal{A}_{t}^{\frac{1-\sigma}{1-\psi}-1} c_{t}^{-\psi} v\left(x_{t}\right)\right|_{\underline{\underline{\mu^{\prime}}}}=c_{t}^{-\sigma}(1-\vartheta)^{\frac{1-\sigma}{1-\psi}}\left(1+\left(\frac{\vartheta}{1-\vartheta}\right)^{\frac{1}{\psi}}\left(\frac{\chi_{t+1}^{m}}{\lambda_{t}}\right)^{1-\frac{1}{\psi}}\right)^{\frac{\psi-\sigma}{1-\psi}} v\left(x_{t}\right) .
\end{aligned}
$$




\section{Combined Equilibrium Conditions Define}

$$
\begin{aligned}
& \Psi_{t}^{x}\left(\chi_{t+1}^{m}\right) \equiv(1-\vartheta)^{\frac{1-\sigma}{1-\psi}}\left(1+\left(\frac{\vartheta}{1-\vartheta}\right)^{\frac{1}{\psi}}\left(\frac{\chi_{t+1}^{m}}{\lambda_{t}}\right)^{1-\frac{1}{\psi}}\right)^{\frac{1-\sigma}{1-\psi}} \\
& \Psi_{t}^{c}\left(\chi_{t+1}^{m}\right) \equiv(1-\vartheta)^{\frac{1-\sigma}{1-\psi}}\left(1+\left(\frac{\vartheta}{1-\vartheta}\right)^{\frac{1}{\psi}}\left(\frac{\chi_{t+1}^{m}}{\lambda_{t}}\right)^{1-\frac{1}{\psi}}\right)^{\frac{\psi-\sigma}{1-\psi}} .
\end{aligned}
$$

The household's optimality conditions for capital and leisure, equations (2) and (3), conditional on optimal money holdings as well as firm choices can then be written as

$$
\begin{aligned}
c_{t}^{-\sigma} v\left(x_{t}\right) \Psi_{t}^{c}\left(\chi_{t+1}^{m}\right) & =\beta \mathbb{E}_{t}\left[R_{t+1}^{k} c_{t+1}^{-\sigma} v\left(x_{t+1}\right) \Psi_{t+1}^{c}\left(\chi_{t+2}^{m}\right)\right], \\
\frac{c_{t}^{1-\sigma}}{1-\sigma} v^{\prime}\left(x_{t}\right) \Psi_{t}^{x}\left(\chi_{t+1}^{m}\right) & =c_{t}^{-\sigma} v\left(x_{t}\right) \Psi_{t}^{c}\left(\chi_{t+1}^{m}\right) w_{t}
\end{aligned}
$$

subject to the firm optimality conditions.

The third equilibrium condition is given by the resource constraint (with $n_{t+1}=0$ ) subject to optimal money holdings as well as firm choices. This can be written as

$$
\begin{aligned}
\kappa_{t+1} & =f_{t}\left(\kappa_{t}, 1-x_{t}\right)+\kappa_{t}(1-\delta)-c_{t}-m_{t+1} \mu_{t} \\
& =f_{t}\left(\kappa_{t}, 1-x_{t}\right)+\kappa_{t}(1-\delta)-c_{t} \Psi_{t}^{r c}\left(\chi_{t+1}^{m}\right), \\
\Psi_{t}^{r c}\left(\chi_{t+1}^{m}\right) & \equiv 1+\left(\frac{\vartheta}{1-\vartheta} \frac{\lambda_{t}}{\chi_{t+1}^{m}}\right)^{\frac{1}{\psi}} \frac{\mu_{t}}{\lambda_{t}} .
\end{aligned}
$$

\section{B Optimality under Assumption 1}

Social Planner Allocation When the social planner opts for deposits then $\zeta_{t+1}^{\star}$ satisfies

$$
\nu_{1, t}\left(\zeta_{t+1}^{\star}, \zeta_{t+1}^{\star}\right)+\nu_{2, t}\left(\zeta_{t+1}^{\star}, \zeta_{t+1}^{\star}\right)=-\rho_{t} \Rightarrow \zeta_{t+1}^{\star}=\left(\frac{\left(\phi_{1, t}+\phi_{2, t}\right)(\varphi-1)}{\rho_{t}}\right)^{\frac{1}{\varphi}} .
$$

The shadow liquidity premium on reserves thus equals

$$
-\nu_{1, t}\left(\zeta_{t+1}^{\star}, \zeta_{t+1}^{\star}\right)=\rho_{t} \frac{\phi_{1, t}}{\phi_{1, t}+\phi_{2, t}} .
$$

Note that $\nu_{1, t}\left(\zeta_{t+1}^{\star}, \zeta_{t+1}^{\star}\right)$ equals its equilibrium counterpart, $\nu_{1, t}\left(\zeta_{t+1}, \zeta_{t+1}\right)$, when $\chi_{t+1}^{r}=$ $\rho_{t} \phi_{1, t} /\left(\phi_{1, t}+\phi_{2, t}\right)$. Also,

$$
\nu_{t}\left(\zeta_{t+1}^{\star}, \zeta_{t+1}^{\star}\right)=\left(\phi_{1, t}+\phi_{2, t}\right)\left(\frac{\left(\phi_{1, t}+\phi_{2, t}\right)(\varphi-1)}{\rho_{t}}\right)^{\frac{1-\varphi}{\varphi}} .
$$

The shadow liquidity premium on deposits therefore is given by

$$
\nu_{t}\left(\zeta_{t+1}^{\star}, \zeta_{t+1}^{\star}\right)+\zeta_{t+1}^{\star} \rho_{t}=\left(\frac{\rho_{t}}{\left(\phi_{1, t}+\phi_{2, t}\right)(\varphi-1)}\right)^{1-\frac{1}{\varphi}}\left(\phi_{1, t}+\phi_{2, t}\right) \varphi .
$$


Ramsey Policy The optimal liquidity premia under the Ramsey policy follow directly from the shadow premia in the social planner allocation. As for the optimal subsidy, note from equation (8a $)$ that optimal bank choices are consistent with the first-best allocation if

$$
\chi_{t+1}^{n \star}=\frac{\tilde{\nu}_{t}\left(-\chi_{t+1}^{r \star}\right)-\theta_{t}^{\star}}{1-\psi} .
$$

Solving this equation for $\theta_{t}^{\star}$ (or substituting the expression for equilibrium $\eta_{n, t+1}$ into the expression for $\theta_{t}^{\star}$ given in proposition 4 yields

$$
\theta_{t}^{\star}=\left(\frac{\rho_{t}}{\left(\phi_{1, t}+\phi_{2, t}\right)(\varphi-1)}\right)^{1-\frac{1}{\varphi}}\left(\psi\left(\phi_{1, t}+\phi_{2, t}\right) \varphi-\phi_{2, t}(\varphi-1)\right) .
$$

\section{Proof of Proposition 6}

We state proposition 6, prove it, and discuss its implications for portfolios and budgets. We consider an intervention which reduces deposit holdings at date $t$ by $\Delta>0$ and increases money holdings at date $t$ by $\lambda_{t}^{-1} \Delta$. To guarantee nonnegativity of deposits, capital holdings, and reserves the intervention $\Delta$ must not be too large ${ }^{43}$

Proposition Suppose condition 1 holds. Consider a policy and equilibrium with deposits, reserves, and no central bank loan. There exists another policy and equilibrium, indicated by circumflexes, with fewer deposits and reserves, more money, a central bank loan, a different ownership structure of capital, possibly household taxes at dates $t$ and $t+1$ whose market value equals zero, and otherwise the same allocation and price system.

The two policies and equilibria coincide except that

$$
\begin{aligned}
& \hat{m}_{t+1}=m_{t+1}+\lambda_{t}^{-1} \Delta, \quad \hat{n}_{t+1}=n_{t+1}-\Delta, \quad \hat{l}_{t+1}=\Delta\left(1-\zeta_{t+1}\right), \quad \hat{r}_{t+1}=r_{t+1}-\zeta_{t+1} \Delta, \\
& \hat{k}_{t+1}=k_{t+1}+\left(1-\lambda_{t}^{-1}\right) \Delta, \quad \hat{k}_{t+1}^{g}=k_{t+1}^{g}-\left(1-\lambda_{t}^{-1}\right) \Delta .
\end{aligned}
$$

The household tax at date $t, \hat{T}_{1, t}$, and the state contingent tax at date $t+1, \hat{T}_{2, t+1}$ (in addition to $\left.\tau_{t+1}\right)$, satisfy

$$
\begin{aligned}
\hat{T}_{1, t} & =\Delta\left\{\nu_{t}\left(\zeta_{t+1}, \zeta_{t+1}\right)-\theta_{t}\right\} \\
\hat{T}_{2, t+1} & =\Delta\left\{\left(1-\lambda_{t}^{-1}\right) R_{t+1}^{k}+\lambda_{t}^{-1} R_{t+1}^{m}-R_{t+1}^{n}-\left(\nu_{t}\left(\zeta_{t+1}, \zeta_{t+1}\right)-\theta_{t}\right) R_{t+1}^{f}\right\} .
\end{aligned}
$$

The central bank loan carries the interest rate

$$
R_{t+1}^{l}=\frac{R_{t+1}^{n}+\left(\nu_{t}\left(\zeta_{t+1}, \zeta_{t+1}\right)-\theta_{t}\right) R_{t+1}^{f}-\zeta_{t+1} R_{t+1}^{r}}{1-\zeta_{t+1}} .
$$

\footnotetext{
${ }^{43}$ Specifically, we impose $\Delta \leq n_{t+1},\left(1-\lambda_{t}^{-1}\right) \Delta \leq k_{t+1}^{g},\left(1-\lambda_{t}^{-1}\right) \Delta \geq-k_{t+1}$, and $\zeta_{t+1} \Delta \leq r_{t+1}$. The assumption that the central bank loan in the initial equilibrium equals zero is a convenient normalization.
} 
Implications for Portfolios and Budgets Note that in an equilibrium with deposits reserves are strictly positive such that $0<\zeta_{t+1}<1$.

The portfolio and policy changes described in the proposition have several implications. First, $\hat{z}_{t+1}=z_{t+1}, \hat{m}_{t+1} \mu_{t}+\hat{n}_{t+1} \nu_{t}\left(\zeta_{t+1}, \zeta_{t+1}\right)+\hat{r}_{t+1} \rho_{t}=m_{t+1} \mu_{t}+n_{t+1} \nu_{t}\left(\zeta_{t+1}, \zeta_{t+1}\right)+r_{t+1} \rho_{t}$, and $\hat{\kappa}_{t+1}=\kappa_{t+1}$; that is, the portfolio changes do not alter effective real balances, the aggregate capital stock, or the total resource costs of operating the payment system. Note that the portfolio changes also leave the reserves-to-deposits ratio, $\zeta_{t+1}$, and thus $\nu_{t}\left(\zeta_{t+1}, \zeta_{t+1}\right)$ unchanged.

Second, the length of the household's balance sheet does not change since the household swaps assets (deposits, money, and capital). In contrast, the balance sheet of a bank shortens (unless $\zeta_{t+1}=0$ ) because the bank holds less reserves and reduces total borrowing (in the form of deposits and central bank loans) but invests the same amount in capital as before the intervention. The balance sheet of the consolidated government expands by $\left(\lambda_{t}^{-1}-\zeta_{t+1}\right) \Delta \lesseqgtr 0$ : The central bank raises additional funds $\Delta / \lambda_{t}$ from households but fewer funds from banks, $-\zeta_{t+1} \Delta$; it passes $\Delta\left(1-\zeta_{t+1}\right)$ through to the banking sector and increases capital holdings by $\left(\lambda_{t}^{-1}-1\right) \Delta$.

Third, the new tax at date $t$ compensates for the reduced bank losses borne by households, $\hat{\pi}_{1, t}^{b}-\pi_{1, t}^{b}=\hat{T}_{1, t}$. Similarly, the new state contingent taxes at date $t+1$ compensate for the change in the return on the household portfolio as well as the change in bank profits that households collect at date $t+144$ The market value of the two taxes as of date $t$ equals zero, $\hat{T}_{1, t}+\mathbb{E}_{t}\left[\operatorname{sdf}_{t+1} \hat{T}_{2, t+1}\right]=0$, and so does the market value of the changes in bank profits ${ }^{45}$ As a consequence, the household's dynamic and intertemporal budget constraints continue to be satisfied with the modified portfolios and policy.

Fourth, the same holds true for the government. From equation (14), the government budget constraint at date $t$ reads $\hat{k}_{t+1}^{g}+\hat{l}_{t+1}-\hat{m}_{t+1}-\hat{r}_{t+1}=k_{t}^{g} R_{t}^{k}-m_{t} R_{t}^{m}-r_{t} R_{t}^{r}+\tau_{t}-$ $\hat{n}_{t+1} \theta_{t}-\hat{m}_{t+1} \mu_{t}-\hat{r}_{t+1} \rho_{t}+\hat{T}_{1, t}$. Condition 1 implies that this equality is satisfied if and only if the budget constraint was satisfied before the intervention. Similarly, the government budget constraint at date $t+1, k_{t+2}^{g}-m_{t+2}-r_{t+2}=\hat{k}_{t+1}^{g} R_{t+1}^{k}+\hat{l}_{t+1} R_{t+1}^{l}-\hat{m}_{t+1} R_{t+1}^{m}-$ $\hat{r}_{t+1} R_{t+1}^{r}+\tau_{t+1}-n_{t+2} \theta_{t+1}-m_{t+2} \mu_{t+1}-r_{t+2} \rho_{t+1}+\hat{T}_{2, t+1}$, is equivalent to the constraint before the change of portfolios and policy.

Proof Conjecture that the price system does not change, as claimed in the proposition. The optimal production decisions of firms are unchanged in this case, as are firm profits. Moreover, the market values of labor income, taxes, and bank profits (as shown above) also do not change. As a consequence, household wealth is unaffected, and so are the optimal consumption and real balances sequences. As shown above, these sequences are supported by the modified portfolios. It remains to be shown that the modified bank

\footnotetext{
${ }^{44}$ The former component equals $\left(\hat{k}_{t+1}-k_{t+1}\right) R_{t+1}^{k}+\left(\hat{m}_{t+1}-m_{t+1}\right) R_{t+1}^{m}+\left(\hat{n}_{t+1}-n_{t+1}\right) R_{t+1}^{n}=(1-$ $\left.\lambda_{t}^{-1}\right) \Delta R_{t+1}^{k}+\lambda_{t}^{-1} \Delta R_{t+1}^{m}-\Delta R_{t+1}^{n}$ and the latter $\hat{\pi}_{2, t+1}^{b}-\pi_{2, t+1}^{b}=-\Delta\left(R_{t+1}^{k}-R_{t+1}^{n}\right)+\Delta\left(1-\zeta_{t+1}\right)\left(R_{t+1}^{k}-\right.$ $\left.R_{t+1}^{l}\right)-\zeta_{t+1} \Delta\left(R_{t+1}^{r}-R_{t+1}^{k}\right)=-\Delta\left(\nu_{t}(\ldots)-\theta_{t}\right) R_{t+1}^{f}$, where we use the expression for the loan rate.

${ }^{45}$ The market value of the two taxes equals $\Delta$ times $\left(\nu_{t}(\ldots)-\theta_{t}\right)+\left(1-\lambda_{t}^{-1}\right)+\lambda_{t}^{-1} R_{t+1}^{m} / R_{t+1}^{f}-$ $R_{t+1}^{n} / R_{t+1}^{f}-\left(\nu_{t}(\ldots)-\theta_{t}\right)=0$, where we use equation $(5)$. The market value of the change in bank profits equals $\hat{\pi}_{1, t}^{b}-\pi_{1, t}^{b}+\mathbb{E}_{t}\left[\operatorname{sdf}_{t+1}\left(\hat{\pi}_{2, t+1}^{b}-\pi_{2, t+1}^{b}\right)\right]=\hat{T}_{1, t}-\Delta\left(\nu_{t}(\ldots)-\theta_{t}\right)=0$.
} 
portfolios are optimal; in that case, all budget constraints are satisfied at the optimal choices, equilibrium capital accumulation is unchanged, and the conjecture is verified.

To render deposits $\hat{n}_{t+1}$, loans $\hat{l}_{t+1}$, and reserves $\hat{r}_{t+1}$ optimal for a bank it suffices for the central bank to supply loans such that the bank's choice sets before and after the intervention coincide. Before the intervention, this choice set is determined by the operating cost function, $\nu_{t}$; the subsidy, $\theta_{t}$; deposit supply as a function of the deposit rate; the stochastic discount factor; and the return on capital. After the intervention, it is defined by the same cost function, subsidy rate, stochastic discount factor, and return on capital; a modified deposit supply function (because households hold more money); and a central bank loan supply function.

To assure identical choice sets it therefore suffices for the central bank to post an appropriate loan supply schedule. This schedule makes up for the shift in the deposit supply schedule, corrected for the fact that $1-\zeta_{t+1}$ dollars of central bank loans provide the same net funding as one dollar of deposits of which $\zeta_{t+1}$ dollars are invested in reserves ${ }^{46}$ Subject to the appropriate loan supply schedule a bank chooses a quantity of loans that makes up for the reduction in funding (net of reserves) from households, at the same effective price; moreover, it chooses the same reserves-to-deposits ratio such that $\nu_{t}\left(\zeta_{t+1}, \zeta_{t+1}\right)$ is unaffected.

\section{Irrelevance of Timing of Household Taxes}

The second equivalence result, which is in the spirit of Barro (1974) and Wallace (1981), establishes a form of Ricardian equivalence. Since taxes are nondistorting and the household and the government have the same time horizon a wealth-neutral change in the profile of household taxes does not alter the allocation if households can undo this change by way of portfolio adjustments. Formally, we have the following result:

Proposition 8. Consider a policy that supports an equilibrium. Consider a modified policy, indicated by circumflexes, which differs with respect to the timing of taxes but not their total value,

$$
\left\{\hat{\tau}_{t}\right\}_{t \geq 0} \neq\left\{\tau_{t}\right\}_{t \geq 0} \text { but } \sum_{t=0}^{\infty} \mathbb{E}_{0}\left[\operatorname{sdf}_{t}\left(\hat{\tau}_{t}-\tau_{t}\right)\right]=0 .
$$

Suppose the government and the household can trade assets such that along each history, the cash flow profile of the asset trades equals $\left\{\hat{\tau}_{t}-\tau_{t}\right\}_{t \geq 0}$ (and the new asset positions do not violate nonnegativity constraints on capital holdings). Then, the modified policy supports an equilibrium. This equilibrium coincides with the initial equilibrium except for the asset positions.

The proof of proposition 8 follows directly from the standard proof of Ricardian equivalence:47 Conjecture that the policy change does not alter prices, and thus household

\footnotetext{
${ }^{46}$ If the banking sector were competitive no pass through funding would be required; equivalence could also be achieved if banks shed assets, see Brunnermeier and Niepelt (2019).

${ }^{47}$ See for example Niepelt $(2019)$
} 
wealth. Since taxes are nondistorting the choice set of households is unchanged and households optimally respond to the modified tax profile by adjusting their asset holdings. To satisfy the government budget constraint the government adjusts its asset holdings in the opposite direction. Since the bank's problem is not affected by the policy change aggregate net asset holdings remain unchanged, verifying the conjecture and proving the result.

One implication of proposition 8 concerns steady states. Consider an economy that is in steady state from date $t=0$ onward; policy supports an equilibrium with household taxes and capital holdings $\left(\tau, k, k^{g}, k^{b}\right)$ where bank capital holdings equal $k^{b}=n+l-r$. Proposition 8 implies that the same policy except for a modified tax profile, namely

$$
\hat{\tau}_{0}=\tau-\Delta, \quad \hat{\tau}_{t}=\tau+\left(R^{k}-1\right) \Delta, t \geq 1, \Delta>0,
$$

supports the same equilibrium except for modified capital holdings, namely

$$
\hat{k}_{t+1}=k_{t+1}+\Delta, \quad \hat{k}_{t+1}^{g}=k_{t+1}^{g}-\Delta, \quad \hat{k}_{t+1}^{b}=k_{t+1}^{b}, t \geq 0 .
$$

That is, there exists another steady state with the same consumption, real balances, prices, and total capital stock, but with household taxes and capital holdings given by $\left(\tau+\left(R^{k}-1\right) \Delta, k+\Delta, k^{g}-\Delta, k^{b}\right)$.

\section{E Data}

We use the quarterly average of the FRED series IOER (2008q4-2019q4) for the nominal interest rate on reserves. Since no interest on reserves was paid prior to 2008 (see https://www.federalreserve.gov/monetarypolicy/reqresbalances.htm) we set $R_{t+1}^{r}=1 / \Pi_{t+1}$ prior to 2008 where $\Pi_{t+1}$ denotes gross inflation. We use the quarterly average of the FRED series CPILFESL_PC1 (Consumer Price Index for All Urban Consumers: All Items Less Food and Energy in U.S. City Average, Percent Change from Year Ago, Index 1982-1984=100, Seasonally Adjusted) for gross inflation.

We use quarterly averages of Kurlat's (2019) monthly estimates (1999m01-2017m12) of the risk-free rate and the deposit rate ${ }^{48}$ Kurlat (2019) provides two estimates of the latter (based on RateWatch data), one based on data for checking accounts and the other for money market accounts. We compute a weighted average of the two estimates where the weights correspond to the relative size of checkable and savings deposits. We use quarterly averages of the FRED series TCDSL (Total Checkable Deposits, Billions of Dollars, Seasonally Adjusted) and SAVIngSL (Savings Deposits - Total, Billions of Dollars, Seasonally Adjusted) for checkable and savings deposits, respectively. We adjust the constructed interest rate series using the inflation series defined before.

We use the quarterly average of the FRED series RESBALNS (Total Reserve Balances Maintained with Federal Reserve Banks, Billions of Dollars, Not Seasonally Adjusted) for reserves. We use two alternative series for deposits. The first series ([a]) is the sum of the quarterly averages of the FRED series TCDSL and SAVINGSL defined before. The

\footnotetext{
${ }^{48}$ We thank Pablo Kurlat for sharing his data.
} 
second series $([\mathrm{b}])$ is the sum of the quarterly average of the FRED series TCDSL and the quarterly money market deposit account (MMDA) series constructed by Lucas and Nicolini (2015).49 We compute $\zeta_{t+1}$ as the ratio of the reserve series and either of the two deposit series. We compute deposits as a share of GDP as the ratio of either of the two deposit series and the FRED series GDP (Gross Domestic Product, Billions of Dollars, Quarterly, Seasonally Adjusted Annual Rate).

We use the quarterly FRED series A587RC1Q027SBEA (Corporate profits with inventory valuation and capital consumption adjustments: Domestic industries: Financial) for banking profits.

\section{References}

Andolfatto, D. (2018). Reconciling orthodox and heterodox views on money and banking, Working Paper 2018-27A, Federal Reserve Bank of St. Louis, St. Louis.

Andolfatto, D. (2019). Assessing the impact of central bank digital currency on private banks, Working Paper 2018-26D, Federal Reserve Bank of St. Louis, St. Louis.

Auer, R. and Böhme, R. (2020). The technology of retail central bank digital currency, BIS Quarterly Review pp. 85-100.

Auer, R., Cornelli, G. and Frost, J. (2020). Rise of the central bank digital currencies: Drivers, approaches and technologies, Working Paper 880, Bank for International Settlements, Basel.

Barrdear, J. and Kumhof, M. (2016). The macroeconomics of central bank issued digital currencies, Staff Working Paper 605, Bank of England, London.

Barro, R. J. (1974). Are government bonds net wealth?, Journal of Political Economy 82(6): 1095-1117.

Benes, J. and Kumhof, M. (2012). The Chicago plan revisited, Working Paper 12/202, International Monetary Fund, Washington.

Bianchi, J. and Bigio, S. (2020). Banks, liquidity management, and monetary policy. Unpublished, Federal Reserve Bank of Minneapolis and UCLA.

Bindseil, U. (2020). Tiered CBDC and the financial system, Working Paper 2351, European Central Bank, Frankfurt.

BIS (2018). Central bank digital currencies, Report, BIS: Committee on Payments and Market Infrastructures, and Markets Committee, Basel.

Bolton, P., Li, Y., Wang, N. and Yang, J. (2020). Dynamic banking and the value of deposits, Working Paper 2020-13, Ohio State University, Fisher College of Business, Columbus.

\footnotetext{
${ }^{49}$ We thank Luca Benati for sharing the MMDA series.
} 
Böser, F. and Gersbach, H. (2020). Monetary policy with a central bank digital currency: The short and the long term, Discussion Paper 15322, CEPR, London.

Brunnermeier, M. K. and Koby, Y. (2018). The reversal interest rate, Working Paper 25406, NBER, Cambridge, Massachusetts.

Brunnermeier, M. K. and Niepelt, D. (2019). On the equivalence of private and public money, Journal of Monetary Economics 106: 27-41.

Bryant, J. (1983). Government irrelevance results: A simple exposition, American Economic Review 73(4): 758-761.

Chamley, C. and Polemarchakis, H. (1984). Assets, general equilibrium and the neutrality of money, Review of Economic Studies 51(1): 129-138.

Chiu, J., Davoodalhosseini, M., Jiang, J. and Zhu, Y. (2019). Bank market power and central bank digital currency: Theory and quantitative assessment, Staff Working Paper 2019-20, Bank of Canada, Ottawa.

Croushore, D. (1993). Money in the utility function: Functional equivalence to a shoppingtime model, Journal of Macroeconomics 15(1): 175-182.

Del Negro, M. and Sims, C. A. (2015). When does a central bank's balance sheet require fiscal support?, Journal of Monetary Economics 73(C): 1-19.

Di Tella, S. (2020). Risk premia and the real effects of money, American Economic Review 110(7): 1995-2040.

Drechsler, I., Savov, A. and Schnabl, P. (2017). The deposits channel of monetary policy, Quarterly Journal of Economics 132(4): 1819-1876.

Farhi, E. and Tirole, J. (2020). Shadow banking and the four pillars of traditional financial intermediation, Review of Economic Studies forthcoming.

Faure, S. and Gersbach, H. (2018). Money creation in different architectures, Discussion Paper 13156, CEPR.

Feenstra, R. C. (1986). Functional equivalence between liquidity costs and the utility of money, Journal of Monetary Economics 17(2): 271-291.

Fernández-Villaverde, J., Sanches, D., Schilling, L. and Uhlig, H. (2020). Central bank digital currency: When price and bank stability collide. Unpublished, University of Pennsylvania.

Fischer, S. (1972). Keynes-Wicksell and neoclassical models of money and growth, American Economic Review 62(5): 880-890.

Fisher, I. (1935). 100\% Money, Adelphi, New York. 
Freixas, X. and Rochet, J.-C. (2008). Microeconomics of Banking, 2. edn, MIT Press, Cambridge, Massachusetts.

Friedman, M. (1969). The optimum quantity of money, in M. Friedman (ed.), The Optimum Quantity of Money and Other Essays, Aldine, Chicago, chapter 1, pp. 1-50.

Galí, J. (2015). Monetary Policy, Inflation, and the Business Cycle, 2. edn, Princeton University Press, Princeton.

Gurley, J. G. and Shaw, E. S. (1960). Money in a Theory of Finance, Brookings Institution, Washington.

Hall, R. E. and Reis, R. (2015). Maintaining central-bank financial stability under newstyle central banking, Working Paper 21173, NBER, Cambridge, Massachusetts.

Kahn, C. M., Rivadeneyra, F. and Wong, T.-N. (2018). Should the central bank issue e-money?, Staff Working Paper 2018-58, Bank of Canada, Ottawa.

Keister, T. and Monnet, C. (2020). Central bank digital currency: Stability and information. Unpublished, Rutgers University and University of Bern.

Keister, T. and Sanches, D. (2020). Should central banks issue digital currency? Unpublished, Rutgers University and Federal Reserve Bank of Philadelphia.

King, R. G., Plosser, C. I. and Rebelo, S. T. (1988). Production, growth, and business cycles I: The basic neoclassical model, Journal of Monetary Economics 21: 195-232.

Kiyotaki, N. and Moore, J. (2019). Liquidity, business cycles, and monetary policy, Journal of Political Economy 127(6): 2926-2966.

Klein, M. A. (1971). A theory of the banking firm, Journal of Money, Credit, and Banking 3(2): 205-218.

Knight, F. H., Cox, G. V., Director, A., Douglas, P. H., Fisher, I., Hart, A. G., Mints, L. W., Schultz, H. and Simons, H. C. (1933). Memorandum on banking reform. Henry C. Wallace papers.

Kumhof, M. and Noone, C. (2018). Central bank digital currencies - design principles and balance sheet implications, Staff Working Paper 725, Bank of England, London.

Kurlat, P. (2019). Deposit spreads and the welfare cost of inflation, Journal of Monetary Economics 106: 78-93.

Lagos, R. and Zhang, S. (2020). The limits of onetary economics: On money as a latent medium of exchange, Working Paper 26756, NBER, Cambridge, Massachusetts.

Lucas, R. E. and Nicolini, J. P. (2015). On the stability of money demand, Journal of Monetary Economics 73: 48-65. 
McCallum, B. T. and Goodfriend, M. S. (1987). Demand for money: Theoretical studies, in J. Eatwell, P. Newman and M. Milgate (eds), The New Palgrave: A Dictionary of Economics, Macmillan Press, London, pp. 775-781.

Monti, M. (1972). Deposit, credit and interest rate determination under alternative bank objective functions, in K. Shell and G. P. Szegö (eds), Mathematical Methods in Investment and Finance, North-Holland, Amsterdam, pp. 431-454.

Niepelt, D. (2018). Reserves for all? Central Bank Digital Currency, deposits, and their (non)-equivalence, Discussion Paper 13065, CEPR.

Niepelt, D. (2019). Macroeconomic Analysis, MIT Press, Cambridge, Massachusetts.

Niepelt, D. (2020). Reserves for all? Central Bank Digital Currency, deposits, and their (non)-equivalence, International Journal of Central Banking 16(3): 211-238.

Parlour, C. A., Rajan, U. and Walden, J. (2020). Payment system externalities. Unpublished, University of California Berkeley and University of Michigan.

Philippon, T. (2015). Has the US finance industry become less efficient? On the theory and measurement of financial intermediation, American Economic Review 105(4): 14081438.

Piazzesi, M. and Schneider, M. (2020). Credit lines, bank deposits or CBDC? competition and efficiency in modern payment systems. Unpublished, Stanford University.

Rocheteau, G. and Nosal, E. (2017). Money, Payments, and Liquidity, 2. edn, MIT Press, Cambridge, Massachusetts.

Sargent, T. J. (1987). Dynamic Macroeconomic Theory, Harvard University Press, Cambridge, Massachusetts.

Saving, T. R. (1971). Transactions costs and the demand for money, American Economic Review 61(3): 407-420.

Sidrauski, M. (1967). Rational choice and patterns of growth in a monetary economy, American Economic Review 57(2): 534-544.

Taudien, R. (2020). Borrowing costs, liquidity and full reserve banking. Thesis paper, University of Bern.

Taylor, J. B. (1993). Discretion versus policy rules in practice, Carnegie-Rochester Conference Series on Public Policy 39: 195-214.

Tobin, J. (1963). Commercial banks as creators of "money", Discussion Paper 159, Cowles Foundation, New Haven.

Tobin, J. (1965). Money and economic growth, Econometrica 33(4): 671-684. 
Tobin, J. (1969). A general equilibrium approach to monetary theory, Journal of Money, Credit, and Banking 1(1): 15-29.

Tobin, J. (1985). Financial innovation and deregulation in perspective, Bank of Japan Monetary and Economic Studies 3(2): 19-29.

Wallace, N. (1981). A Modigliani-Miller theorem for open-market operations, American Economic Review 71(3): 267-274.

Walsh, C. E. (2017). Monetary Theory and Policy, 4. edn, MIT Press, Cambridge, Massachusetts.

Williamson, S. (2019). Central bank digital currency: Welfare and policy implications. Unpublished, University of Western Ontario.

Woodford, M. (2003). Interest and Prices, Princeton University Press, Princeton. 